Bulletin of SOAS, 79, 2 (2016), 347-374. (c) SOAS, University of London, 2016. doi:10.1017/S0041977X16000070

\title{
A Phonological History of Amdo Tibetan Rhymes
}

\author{
Xun Gong \\ (author's draft) \\ Centre de recherches linguistiques sur l'Asie orientale \\ INALCO/CNRS/EHESS \\ gong@phare.normalesup.org
}

\begin{abstract}
In this study, a reconstruction is offered for the phonetic evolution of rhymes from Old Tibetan to modern-day Amdo Tibetan dialects. The relevant sound changes are proposed, along with their relative chronological precedence and the dating of some specific changes. Most interestingly, although Amdo Tibetan, identically to its ancestor Old Tibetan, does not have phonemic length, this study shows that Amdo Tibetan derives from an intermediate stage which, like many other Tibetan dialects, does make the distinction.
\end{abstract}

\section{Introduction}

Amdo Tibetan, a dialect complex of closely related Tibetan varieties spoken in the Chinese provinces of Qinghai, Gansu and Sichuan, is, demographically, linguistically and culturally, one of the most important dialects of Tibetan. The historical phonology of syllable onsets of Amdo Tibetan is well studied (Róna-Tas, 1966; Sun, 1987), notably for its fascinating retentions and innovations of the complex consonant clusters of Old Tibetan (OT). The rhymes (syllable nuclei and coda) have received less attention.

${ }^{*}$ This work is related to the research strand PPC2 Evolutionary approaches to phonology: New goals and new methods (in diachrony and panchrony) of the Labex EFL (funded by the ANR/CGI). I would like to thank Guillaume Jacques and two anonymous reviewers for various suggestions which resulted in a more readable and better-argued paper. 
This study aims to reconstruct the phonetic evolution of rhymes from Old Tibetan ${ }^{1}$ to modern-day Amdo Tibetan dialects. Most interestingly, Amdo Tibetan will be shown to derive from a language which, like other Tibetan dialects, has phonemic vowel length.

The primary source of data of this study comes from Hua (2002), a glossary of 6 Amdo dialects: Bsang.chu (BsA), Reb·gong (ReB), Ya·rdzi (YAR), Ba·yan (BAY), Dmar.thang (DMA) and Them.chen (THE) ${ }^{2}$. Work on individual dialects is consulted when possible: For BsA, reference is made to Hua and Longbojia (1993), a dictionary of the dialect of Labrang town; for DMA, to (Sun, 1986), describing a

\footnotetext{
${ }^{1}$ The terms Old Tibetan and Written Tibetan (see Hill, 2010 for further discussion) are not unproblematic, so a few word must be said to clarify my use of them. For the purposes of this paper, Written Tibetan is recognized to possess a kernel which is phonologically equivalent to Old Tibetan, the language of the Tibetan empire. Hence Written Tibetan forms are freely taken to supplement the Old Tibetan material. Words are cited in 'orthography', in other words, the (sometimes reconstructed) form which corresponds to the modern forms. Cases where the 'orthographical' form diverges from actual Old Tibetan or Written Tibetan are marked with asterisks, with the attested forms given later. Morpheme-by-morpheme equivalents from modern dialects to Old/Written Tibetan are labeled "OT" with sarcastic quotation marks. The language is always refered as Old Tibetan, so as to recognize the essentially pastiche character of Written Tibetan.

${ }^{2}$ The Bsang.chu speaker comes from Rgan.gya township (Chinese: Xiàhé-xiàn Gānjiāxiāng); the Reb.gong speaker from the famously multiethnic Gnyan·thog township (Tóngrénxiàn Niándūhū-xiāng); the Ya.rdzi speaker from Sgo·ris village in Rdo·sbis township (Xúnhuàxiàn Dàowěi-xiāng Gǔléi-cūn), the Ba-yan speaker from Chu·dmar township (Huàlóng-xiàn Chūmá-xiāng), the Dmar-thang speaker from Zangs·dkar township (Hóngyuán-xiàn Răngkǒu/ Ràngkǒu-xiāng), the Them·chen speaker from 'Brug·khyung township (Tiānjùn-xiàn Zhōuqúnxiāng).

Unlike in Tibetan Autonymous Region or Khams, PRC counties in the Northeastern part of the Tibetan-speaking area are products of Chinese administrative history and rarely coincide with the locals' geographic conception, for which reason the Tibetan names of the counties exhibit a great variation. All counties except Them.chen (whose Chinese name comes from Tibetan) are usually known in transcriptions from the Chinese: Zhà.ho, Thun.rin, Zhun.hwa, Hwa.lung and $H u n g \cdot y(o / e) n$, as can be seen in for example Hua and Longbojia (1993) Bsang.chu County, a name calqued from the Chinese, is also known after its principle town as Labrang County. Townshiplevel placenames are usually of Tibetan origin, in Tibetan and Chinese, and therefore do not exhibit this kind of flux.

The data is cited in the original IPA spelling, with two changes: the Chinese IPA variant of palatal nasal, $n$, is normalized to $n$; prenasalization, indicated by full-sized $n$ in the original, is changed to the superscript ${ }^{n}$. The words are referenced with the numbering in the original.
} 
similar dialect from Mdzod.dge ${ }^{3}$; for The, to Haller (2004) $)^{4}$. Mostly fragmentary data on other dialects are refered to where relevant. The locality of the dialects refered to in this study is represented on Figure 1.

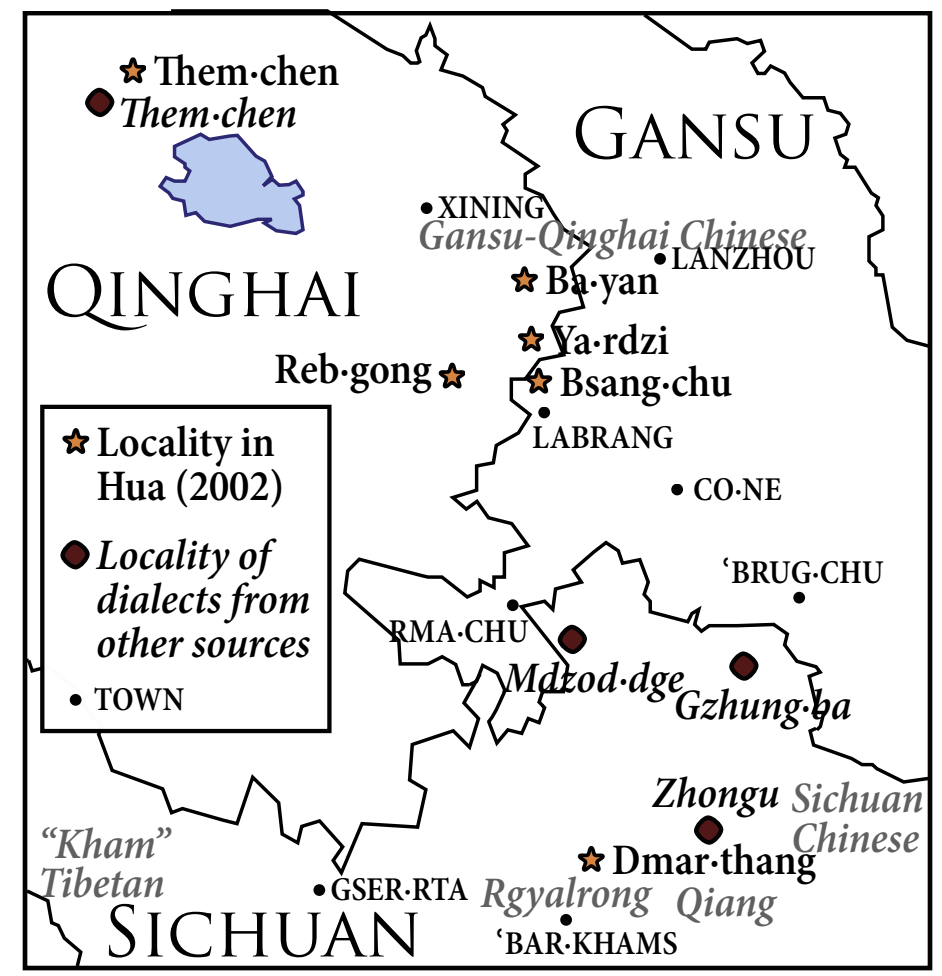

Figure 1: Map of Tibetan dialects refered to in this study and neighbouring languages

Idiosyncratic changes happen in dialects, making perfect correspondence impossible; a work of the scope of Hua (2002) (and the other monographs) necessarily contains its share of misprints and mistranscriptions. No claim of exhaustiveness is made concerning their classification and explanation, with one partial exception: because of the importance of rhymes giving modern $i$ and $e$ in this

${ }^{3}$ The speaker is from Byams-me township (Ruòěrgài-xiàn Xiámàn-xiāng). Hill (2009), an excellent reference to the geography of Tibetan dialects in general, misread the original to give WT $m d z o \cdot d g e \cdot s d e \cdot p a$. In fact, sde.pa was meant to be the generic term for 'district', while the Written Tibetan equivalent for $6 æ m e$ was not given.

Sun uses IPA for the phonetic transcription and a semi-IPA system for the phonemic transcription. In the latter system, alveolo-palatals are indicated as ś, retroflexes as $\boldsymbol{s}$, etc. This is normalized to the IPA usage akin to that in his phonetic transcription.

${ }^{4} \mathrm{His}$ informants come from Brag.dmar township (Zhīhémă-xiāng). 
study, alternations and irregular correspondences between these two vowels are studied in detail.

Among the 6 dialects described in Hua (2002), BAY is highly deviant: among its many anomalies, the form for numerals 'eight' (OT brgyad, \#1067) and 'hundred' (OT brgya, \#1098) had hbj-initials: hbic and hbia'; the form for 'hand' (OT lag.pa \#139) has as initial 4-; the word smon.lam is pronounced hno.lan.

The other 5 dialects in Hua (2002) show mostly regular phonological correspondences to each other, and they are considered as belonging to the same group, named Core Amdo for the purpose of this study. As BAY is nevertheless close to Core Amdo dialects, it will be presented and discussed along with other dialects from Hua (2002). However, no reconstruction decision will be based on it.

The reflexes of Tibetan rhymes in di- or polysyllabic words often depend on the position of the syllable containing the rhyme, a non-final syllable often having radically divergent outcomes from a final one (see Jacques (2011) and Sun (2006) for some extreme examples). Fortunately, the effect of this phenomenon is very limited in Amdo Tibetan, and cases where this happens will be mentioned in an ad-hoc manner.

This study begins with Section 2, where correspondence sets of rhymes are identified among the Amdo dialects, represented as rhymes of the proto-language, called also Core Amdo (CA). In Section 3, it will be demonstrated that the vowel system of Core Amdo goes back to one with phonemic vowel length. With this insight, I try to give a relative chronology of the phonetic changes from Old Tibetan to the Core Amdo dialects in Section 4, along with some absolute dating with recourse to loanwords.

\section{Internal correspondences in Amdo}

In this section, I will present the correpondence of rhymes among the Core Amdo dialects. For each correspondence set, a reconstructed rhyme will be given. In other words, the most recent ancestor of Core Amdo dialects, labeled Core Amdo, will be reconstructed in this section. The usual precautions apply, that Core Amdo is meant as a convenient representation of the reconstructible features, and may never have existed as an actual spoken variety. In other words, by the time that some features reconstructed for Core Amdo came into being, changes may had already created some of the dialect divisions in the Core Amdo area.

\footnotetext{
${ }^{5} \mathrm{~A}$ possible interpretation is that this form comes from pre-Tibetan ${ }^{\star} b r y a(d)$ by a simple metathesis, predating Li's law (For the naming of sound laws concerning Tibetan, see Hill, 2011) that changes ${ }^{\star} r j$ - to $r g y$ - $\left(\mathrm{rg}^{j}\right)$. The decade form of eight, though, is still derived from $g y a$, but it could be a later influence from literary Tibetan.
} 
The reconstructed Core Amdo system has 12 vowels, shown in Figure 2. Among the Core Amdo vowels, ${ }^{\star} a,{ }^{\star} e,{ }^{*} o,{ }^{\star} \partial$ can be followed by codas, one of ${ }^{\star} p,{ }^{*} t,{ }^{\star} k$, ${ }^{\star} m,{ }^{\star} n,{ }^{\star} \eta,{ }^{\star} r$. The other vowels can only occur in open syllables.

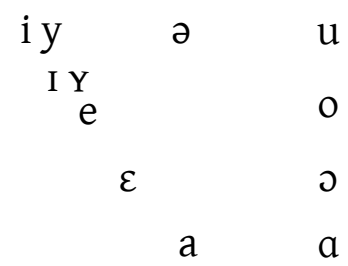

Figure 2: Vowels in reconstructed Core Amdo

For the convenience of the reader, a chart showing the most common correspondence from Old Tibetan to Core Amdo is given first, as Table 1.

\begin{tabular}{|c|c|c|c|c|c|c|c|c|c|c|c|c|}
\hline & $\varnothing$ & b & $\mathrm{d}$ & $\mathrm{g}$ & $\mathrm{m}$ & $\mathrm{n}$ & $\mathrm{ng}$ & $r$ & 1 & $\mathrm{~s}$ & -ba & -bo \\
\hline $\mathrm{a}$ & $a$ & ap & at & ak & $\mathrm{am}$ & an & ay & ar & $a$ & I & $\mathrm{a}$ & $\mathrm{u}$ \\
\hline $\mathrm{i}$ & $\partial$ & әр & วt & ək & əm & วn & an & $\partial r$ & $\mathrm{i}$ & $\mathrm{i}$ & $\varepsilon$ & \\
\hline $\mathrm{u}$ & $\partial$ & әр & $\partial t$ & ək & əm & ən & on & ər & $\mathrm{u}$ & $\mathrm{y}$ & Ј & $\mathrm{u}$ \\
\hline $\mathrm{e}$ & $\mathrm{e}$ & ep & et & ak & $\mathrm{em}$ & en & an & er & $\mathrm{i}$ & I & $\varepsilon$ & \\
\hline 0 & 0 & op & ot & ok & om & on & on & or & $\mathrm{u}$ & $\mathrm{Y}$ & כ & $\mathrm{u}$ \\
\hline
\end{tabular}

Table 1: Most common rhyme correspondence between Old Tibetan and Core Amdo

In 2.1, the consonant codas in Core Amdo will be discussed, with regard to their origin, their realizations and their influences on the syllable nucleus. Then the discussion will begin with vowels that can take codas, then vowels deriving from a lost Old Tibetan coda, and after that vowels deriving from syllable fusion. Lastly, a conclusion will highlight the characteristic changes of each dialect - and archaisms of BAY - and the evolution of Old Tibetan rhymes to Core Amdo.

\subsection{Overview of rhymes with consonant coda}

In Core Amdo, only four vowels occur in closed syllables: ${ }^{\star} a,{ }^{\star} \partial,{ }^{\star} e$ and ${ }^{\star} o$. Therefore one example will be shown for every coda with each of the four nuclei.

\subsection{1 ${ }^{\star}-t,{ }^{\star}-n,{ }^{\star}-r$}

First, I will examine the coronal codas, starting with ${ }^{\star}-t$ (Table 2). The coda ${ }^{\star}-t$, which always comes from OT $-d$, has its pausal forms transcribed -1 in BsA and 


\begin{tabular}{|c|c|c|c|c|c|c|c|c|}
\hline CA & & BSA & REB & YAR & DMA & THE & BAY & \\
\hline & tshad 'to $\mathrm{n}$ & tshal & tshal & tshe & tshat & tshal & tshe & 1462,1777 \\
\hline$-\partial t$ & khrid 'to lead.Pst' & tchəl & cçhəl & tchว & cçh & tcḩəl & tchə & 1527,1847 \\
\hline -et & khed 'riddle' & khel & khe & khe & khet & khel & khe & 822 \\
\hline$-o t$ & 'phrod 'to receive' & tşhol & tşhø & tşho & mtshot & mtshol & tsho & 1909 \\
\hline
\end{tabular}

Table 2: Modern reflexes of $\mathrm{CA}^{*}-t$

\begin{tabular}{ll|ccccccl} 
CA & & BSA & REB & YAR & DMA & THE & BAY & \\
\hline -an & rkan 'palate' & hkan & hkan & hkan & rkan & rkan & hkan & 176 \\
-ən & sprin 'cloud' & Sən & Sən & sən & fən & wtsən & Sən & 8 \\
-en 'ben 'target' & nben & nban & nban & mben & mben & nban & 781 \\
-on & thon 'to arrive' & thon & thøn & thon & thon & thon & thon & 1481,1538
\end{tabular}

Table 3: Modern reflexes of $\mathrm{CA}^{*}-n$

The, - $t$ in DMA, and lost in YAR and BAY; the ReB forms present an interesting mix: the coda is lost after mid vowels, but retained as -1 after $/ a /$ and $/ \partial /$. The lost codas create new vowels in ReB, YAR and BAY: $/ \varnothing /<{ }^{\star}$ ot in ReB, $/ \varepsilon /<{ }^{\star}$ at in YAR, and $/ \varepsilon /<{ }^{*}$ at, et as well as $/ \mathrm{\partial} /<^{*}$ ot in BAY.

This coda is notoriously volatile in Amdo dialects. Even in dialects where it is preserved, it is lost or totally assimilated in various cases. For Mdzod.dge, Sun (1986, p.36) indicated that the alternant of /-d/ is [ $\varnothing]$ in a word-internal preconsonantal environment, where the following consonant is neither a nasal nor homorganic (coronal). For BsA, ReB and THE, it is mentioned in Hua (2002) that this coda is often lost in connected speech. Similarly, in the Them.chen dialect described in Haller $(2004$, p.32), it is mentioned that in rapid speech -1 is assimilated to the following morpheme: wəs-s ${ }^{h} u \eta<w a l-s^{h} u \eta$ 'went' ("OT": bud.song).

The coda ${ }^{*}-n$ remains /-n/ in all the dialects surveyed (Table 3). In ReB, YAR and $\mathrm{BAY},{ }^{*}$-an and ${ }^{*}$-en have merged, giving what is transcribed as -an. The outcome looks strange but is not: -an is phonetically front in all three dialects: [æn].

The coda ${ }^{\star}-r$ is lost in YAR but preserved in all other dialects (Table 4). YAR and BAY shows an interesting contrast: in YAR, ${ }^{*}-r$ behaves like ${ }^{*}-t$, or indeed ${ }^{*}-p$ as well, as we will soon see, vanishing with the only trace on the vowel quality of ${ }^{\star}$ a; in $\mathrm{BAY}^{*}-r$ behaves like ${ }^{\star}-n$, in that ${ }^{*}$-ar and ${ }^{\star}$-er have merged as -ar, phonetically [-ær].

\subsection{2 ${ }^{\star}-p,{ }^{\star}-\mathrm{m}$}

Labial codas (Table 5,6) behave similarily to coronal codas. They remain /-p/ and /-m/ in BsA, ReB, DMA and The; in the agricultural dialects of YAR and BAY, 


\begin{tabular}{ll|ccccccl} 
CA & BSA & REB & YAR & DMA & THE & BAY & \\
\hline -ar & mkhar 'city' & khar & khar & khe & mkhar & mkhwar & khwar & 97 \\
-ər & btsir 'to squeeze' & tsər & tsər & htsə & ptsər & ptsər & tsər & 1684 \\
-er & gser 'gold' & ser & ser & hse & hser & hser & hsar & 66 \\
-or & skyor 'to support.PRs' & htcor & hcçor & htco & rcçor & rtcor & htcor & 1450,1606
\end{tabular}

Table 4: Modern reflexes of $\mathrm{CA}^{*}-r$

\begin{tabular}{ll|ccccccl} 
CA & & BSA & REB & YAR & DMA & THE & BAY & \\
\hline -ap & khab 'needle' & khap & khap & khe & khap & khap & khe & 712 \\
-əp & $r d i b$ 'to fall to pieces' & hdəp & hdəp & hdə & rdəp & rdəp & hdə & 1827,1936 \\
-ep & lteb 'to fold up.PRs' & htep & htep & hte & rtep & rtep & hte & 1554 \\
-op thob 'to get' & thop & thop & tho & thop & thop & thə & 1539
\end{tabular}

Table 5: Modern reflexes of $\mathrm{CA}^{*}-\mathrm{p}$

\begin{tabular}{|c|c|c|c|c|c|c|c|c|}
\hline CA & & BSA & REB & YAR & DMA & THE & BAY & \\
\hline $\begin{array}{l}\text {-am } \\
\text {-əm }\end{array}$ & $\begin{array}{l}\text { gnam 'sky, rain' } \\
\text { zhim.po 'tasty' }\end{array}$ & $\begin{array}{c}\text { hnam } \\
\text { cəm }\end{array}$ & $\begin{array}{c}\text { hnam } \\
\text { cəm }\end{array}$ & $\begin{array}{c}\text { hnan } \\
\text { cən }\end{array}$ & $\begin{array}{c}\text { hnam } \\
\text { gəm }\end{array}$ & $\begin{array}{c}\text { hnam } \\
\text { cəm }\end{array}$ & $\begin{array}{c}\text { hnan } \\
\text { cən }\end{array}$ & $\begin{array}{l}1,11 \\
1338,1360\end{array}$ \\
\hline -em & $\begin{array}{l}\text { lcags.khem 'iron shovel' } \\
\text { ' 'bear' }\end{array}$ & $\begin{array}{c}\text { khem } \\
\text { tom }\end{array}$ & kem & khen & khem & khem & khan & 755 \\
\hline
\end{tabular}

Table 6: Modern reflexes of $\mathrm{CA}^{*}$ - $\mathrm{m}$

${ }^{*}-p$ is lost, along with ${ }^{*}-t$, while ${ }^{*}-m$ merged with ${ }^{\star}-n$ as $/-n /$.

There is an interesting issue of rule ordering between YAR and BAY: in YAR, -en is lowered to -an before ${ }^{*}$ - $m$ became $-n$, so ${ }^{*}$-em gives -en, different from ${ }^{\star}$-en; in BAY, it is the other way round: ${ }^{\star}-m$ and ${ }^{\star}-n$ merged first, so ${ }^{\star}$-em became -an along with ${ }^{\star}$-en.

\subsection{3 ${ }^{\star}-k,{ }^{*}-\eta$}

Rhymes with $\mathrm{CA}^{*}-k$ and ${ }^{*}-\eta$ (Table 7) transparently derive from Old Tibetan rhymes in $-g(s)$ and $-n g(s)$, but they have the peculiarity that they witness further mergers in nuclear quality: OT -ag and -eg merge as -ak; OT -ang, -eng and -ing merge as -ay; OT -ong and -ung merge as -oy. Thus, while there are four possible nucleus vowels before other codas, there are only two before ${ }^{\star}-\eta\left({ }^{\star} a,{ }^{\star} o\right)$ and three before ${ }^{\star}-k\left({ }^{\star} a,{ }^{\star} \partial,{ }^{\star} o\right)$. Regularly, all the CA rhymes with ${ }^{\star}-k$ and ${ }^{\star}-\eta$ remain unchanged in the dialects.

The categorical transcription as /-k/ conceals two important and rather uni- 


\begin{tabular}{|c|c|c|c|c|c|c|c|c|}
\hline CA & & BsA & REB & YAR & DMA & THE & BAY & \\
\hline -ak & bregs 'to reap.PsT' & $\overline{\text { tşak }}$ & tşak & tşak & ptsak & ptsak & tsak & $1696,1908,1623$ \\
\hline -ək & (d)myig 'eye' & hjək & hjək & hyək & hjək & hjok & hjək & 110 \\
\hline -ok & glog 'lightning' & hlok & hlok & hlok & hlok & hlok & hlok & 21 \\
\hline -ay & snying 'heart' & hyay & hyay & hnay & rjay & rjạ & hyan & 180 \\
\hline -on & 'brong 'wild yak' & ${ }^{\mathrm{n}} \mathrm{dz}$ zon & ${ }^{\mathrm{n}} \mathrm{dz}$ on & ${ }^{\mathrm{n}} \mathrm{dz}$ on & mdion & mdionon & ${ }^{\mathrm{n}} \mathrm{dz}$ on & 389 \\
\hline
\end{tabular}

Table 7: Modern reflexes of $\mathrm{CA}^{*}-k$ and ${ }^{\star}-\eta$

\begin{tabular}{c|cccccc} 
CA & BSA & REB & YAR & BAY & DMA & THE \\
\hline -ak & $\mathrm{ex}$ & $\mathrm{e} \chi$ & $\mathrm{e} \chi$ & $\mathrm{ek}$ & $\mathrm{ex}$ & $\mathrm{e} \chi$ \\
-ək & $\mathrm{ux} \sim \mathrm{ur}$ & $\mathrm{ux} \sim \mathrm{ur}$ & $\mathrm{ux} \sim \mathrm{ur}$ & $\mathrm{ux} \sim \mathrm{ur}$ & $\mathrm{ux} \sim \mathrm{ur}$ & $\mathrm{ux} \sim \mathrm{ur}$ \\
-ok & ox & o $\chi$ & ox & ox & - & -
\end{tabular}

Table 8: Phonetic transcriptions of $\mathrm{CA}^{\star}-k$ rhymes (Hua, 2002)

form phonetic facts about the nonnasal velar coda: spirantization and uvularization. Spirantization refers to the phenomenon that /-k/ almost always has a realization ranging from fricative to approximant. Uvularization refers to the fact that the realization is a uvular /q $\sim \chi \sim \mathrm{B} /$ after the back vowels $/ \mathrm{a} / \mathrm{and} / \mathrm{o} /$.

The modern realizations of the rhymes transcribed with a velar stop coda are put in Table 8, with data taken from the phonology section in Hua (2002). The items with a dash are not mentioned in Hua's discussion of allophones of vowels and coda consonants. In Brag.dmar Them.chen (Haller, 2004), the reflexes of the

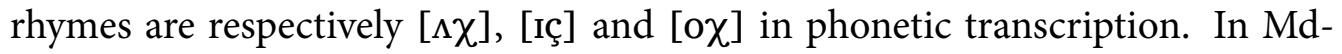

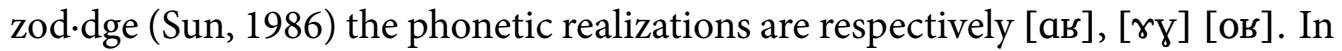
Labrang, "some people" (Gesang-Jumian and Gesang-Yangjin, 2002, p.204) pro-

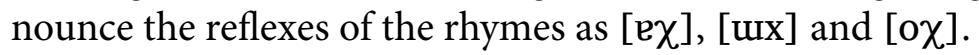

The evidence from these dialects suggests that inconsistencies in Table 8 more likely reflects occasional errors ${ }^{6}$ and the two processes can be reconstructed at the level of Core Amdo.

Judging from the current evidence, a strong case could be made that the uvular pronunciation of OT $-g$ after the vowels $a$ and $o$ can be reconstructed for Old Tibetan. In almost every dialect of Tibetan, there is something that shows the effect of a uvular coda for -ag or $o g$.

- In Western Tibetan (Zemp, 2006), there is a complementary distribution between coda $-k$ and $-q$ : $-q$ after $a$ and $o$; $-k$ after $e, i$ and $u$. The rhyme -ek is secondary (mostly loans): Old Tibetan -eg turned into -jaq in Western Tibetan, like CA*-ak < OT -eg (Jacques, 2009).

\footnotetext{
${ }^{6}$ Or simply misprints, as the symbol for $\chi$ used in Hua (2002), $x$, is misleadingly similar to $x$.
} 
- In Lhasa Tibetan, the coda-less variant of words of the Old Tibetan rhyme - $o g$ is ग? (Goldstein and Nawang, 1970; DeLancey, 2003): the former uvular coda leaves its trace in the retracted tongue root of the vowel.

- In Shigatse Tibetan (Haller, 2000; Jäschke, 1883, p.5-6; Qu, 1991, p.157), og gives oa, which can be compared with Contemporary Standard German $-\boldsymbol{e}<-\boldsymbol{b}$, or the Tiberian Hebrew offglide inserting rule (Prince, 1975, p.9), where a vowel $a$ is inserted word-finally between a non-low vowel and a consonant belonging to the class $\left\{, h, h\right.$ : šolēạ $<{ }^{\star}$ šolēḥ 'sending.

- In Co.ne Tibetan (Jacques, 2011, p.12) spoken in Nyin·pa, OT -ag, -eg, -og has the coda $-q$ when not word-final.

- Among non-Amdo "Archaic" dialects from Eastern Tibet, Kha·long (Sun,

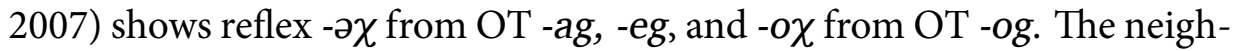
bouring Gser-pa (Sun, 2006) shows word-final -ua for all three ${ }^{7}$.

There remains an important phenomenon that influenced the outcome of OT -ng and - $g$ : what would have become -an and -ak sometimes has as actual outcome -on and -ok. This labialization varies dialectally - it is less frequent in DMA than elsewhere and completely absent in Mdzod.dge (Sun, 1986) ${ }^{8}$ - and idiolect-internally with several factors: it is frequent when followed by the nominalizing suffix -wa (<OT $-p a$ or $-b a)$, and rare elsewhere; within the former case, it is frequent in everyday nouns and unattested in literary loans and adjectives. For the absence of rounding in adjectives, the reason probably has to do with the grammar of adjectives: they occur without suffix as stative verbs and suffixed (with -wa besides other suffixes inherited from OT) as nominal appositions: 'dzapar maywo (more usually may(w)a) 'a lot of photos', 'dzapar may kə 'Photos abound' (Sung and Rgyal, 2005, p.167; cf. Haller, 2004, p.54). A quasiinflectional ablaut (moy may) in this case would be hard to maintain. ${ }^{9}$

\footnotetext{
${ }^{7}$ Sun (2006) analyses the Gser-pa reflexes as coming from a nucleus-coda flip-flop *-ay > -ша. Here I suggest another analysis, taking into account the word-medial form - $\varepsilon k$ (See Sun (2006) for details about word-final and word-medial forms). In my analysis, the starting point should be reconstructed as *-eq. The medial form is a secondary markedness-reduction, and the final form comes from an vocalization or epenthesis similar to what happened in Shigatse, ${ }^{*}$-eq $>{ }^{*}$-ea $>$-ua.

${ }^{8}$ This absence might have been dismissed as an influence from the literary language if not for the fact that Sun is an extremely reliable transcriber: he succeeded in making out the prenasalization in the word ${ }^{n} k^{h}$ ajwæ 'house' (p.220), doubly difficult first because the prenasalization before a voiceless stop is almost inaudible in pausa, secondly as it is not supported by the literary form: OT khang.pa. Hua (2002) has kh- on all his forms of this word (\#616).

${ }^{9}$ However, in Rma.chu Tibetan (Zhoumaocao, 2004), yag.po 'beautiful' has as verbal and nominal forms jak and jok.kwo respectively. This likely reflects the older state before analogy.
} 


\begin{tabular}{ll|ccccccl} 
CA & & BSA & REB & YAR & DMA & THE & BAY & \\
\hline -a & $s a$ 'earth' & sha & sha & sha & sha & sha & sha & 27 \\
-a & $m t h a^{\prime}$ 'edge' & tha & tha & tha & mtha & mtha & tha & 987,2120 \\
-a & $z a$ 'to eat.PRs' & sa & sa & sa & za & sa & sa & 1471
\end{tabular}

Table 9: Modern reflexes of $\mathrm{CA}^{*}$-a

\begin{tabular}{|c|c|c|c|c|c|c|}
\hline CA & BSA & REB & YAR & BAY & DMA & THE \\
\hline$-a$ & $\bar{a}$ & $\underline{a}$ & $\bar{a}$ & $\underline{a}$ & æ & $\underline{a}$ \\
\hline -ap & æp & æp & $/ \varepsilon /$ & $/ \varepsilon /$ & æp & æp \\
\hline -at & $\varepsilon \mathrm{l}$ & $\varepsilon l$ & $/ \varepsilon /$ & $/ \varepsilon /$ & $\varepsilon \mathrm{t}$ & $\varepsilon l$ \\
\hline -ak & ex & $\mathrm{e} \chi$ & $\mathrm{e} \chi$ & ek & ex & $\mathrm{e} \chi$ \\
\hline -am & æm & æm & æn & æn & æm & æm \\
\hline -an & $\varepsilon n$ & $\varepsilon n$ & æn & æn & æn & æn \\
\hline -ay & en & ey & ey & ey & en & ey \\
\hline -ar & ær & ær & $/ \varepsilon /$ & ær & ær & ær \\
\hline
\end{tabular}

Table 10: Phonetic realizations of rhymes with $\mathrm{CA}^{*} \mathrm{a}$

\section{$2.2{ }^{*} a$}

\subsubsection{Open rhyme}

In open syllables, CA ${ }^{*}$ (Table 9), which comes from OT $a$, gives /a/ in all dialects. In DMA (Hua, 2002, p.36) and Mdzod.dge (Sun, 1986), both Southeastern varieties spoken in Sichuan, ${ }^{\star} a$ in an open syllable is raised, approaching [æ]. Hence this vowel is noted $æ$ in (Sun, 1986): the words in Table 9 are transcribed respectively as $s^{h} æ,{ }^{n}$ thæ and $s æ$.

\subsubsection{Closed rhyme}

In closed syllables, OT $a$ always gives CA ${ }^{*}$ a. Additionally, ${ }^{*}$-ak may come from OT -eg(s), ${ }^{*}$-an from OT -eng(s) and -ing(s).

Compared with the usually low central quality in open syllables, ${ }^{*}$ a shows a higher vowel quality in closed syllables. In YAR and BAY, where some codas were lost, the erstwhile allophonic difference has been phonologized as another vowel $/ \varepsilon /$. In Table 10, the reflexes are given in phonetic transcription (following the phonology section of respective dialects in Hua (2002)), and the phonologized reflexes are given in pairs of slashes. ${ }^{10}$

\footnotetext{
${ }^{10}$ [a] represents the low central vowel, [A] in Chinese linguistic tradition.
} 


\begin{tabular}{ll|ccccccl} 
CA & & BSA & REB & YAR & DMA & THE & BAY & \\
\hline -e & mye 'fire' & ne & ne & ne & mje & mje & ji & 19,1690 \\
-e & sre 'to mix.PRs' & Se & Se & se & se & se & si & 1451,1674 \\
-e & je 'more' & tce & tce & tce & tce & - & tci & 1577,1695 \\
-e & de.ring 'today' & te & te & te & te & te & ti & 990
\end{tabular}

Table 11: Modern reflexes of $\mathrm{CA}^{*}-\mathrm{e}$

\begin{tabular}{ll|ccccccc} 
CA & & BSA & REB & YAR & DMA & THE & BAY & \\
\hline -e & seng.ge 'lion' & ge & ge & ge & khe & ge & gi & 384 \\
-e & 'scissors'11 & $\chi$ e.dzə & $\chi$ e.jjə & - & $\chi$ e.jjə & $\chi$ e.mək & khi.dzi & 715
\end{tabular}

Table 12: $\mathrm{CA}^{*}$-e in loan nouns

In Mdzod.dge, $\mathrm{CA}^{*}$-an and ${ }^{*}$-at become -en and -ed. Furthermore, the reflex of CA -ay and -ak are phonetically [aN] and [as] in Mdzod.dge, with a low back vowel. These rhymes are transcribed, unlike in Hua (2002), as -an and -ag, with the vowel /a/, which corresponds to $\mathrm{CA}^{*} a$ in open syllables.

\section{$2.3{ }^{\star} \mathrm{e}$}

\subsubsection{Open rhyme}

Core Amdo vowel ${ }^{*} e$ derives from the Old Tibetan vowel $e$. Regularly, it remains $e$ in all dialects of Hua (2002) except BAY, where it is raised to $i$. This is the case in the most reliable words, in other terms, the words least liable to interdialect loan or sporadic change (Table 11). The same is true for in most nouns, including loans (Table 12).

However, in some words the BAY form shows an unexpected e. Some are mere misprints, as BAY tshe < OT tshe 'life' (\#204) besides tshi ci.ma $<$ tshe phyi.ma 'the next life' (\#854) or interdialectal borrowings, as the decade forms $6 \mathrm{e}$ 'forty' and re 'sixty' (\#1086, \#1090), which confirms the general impression that BAY decade forms are borrowed. There is nevertheless one type of $e<\mathrm{CA}^{\star} e<\mathrm{OT}$ $e$ that is regular, namely when before a non-fusional OT $p a / b a$ : hde.wa $<\mathrm{OT}$ sde.pa 'village' (\#99), hge.wa < OT dge.ba 'good conduct' (\#854).

\footnotetext{
${ }^{11}$ The word for 'scissors' is from Mongolic, cf. Mongolian qayiči. The second syllable is likely contaminated from OT gri 'knife.'
} 


\begin{tabular}{ll|ccccccc} 
CA & BSA & REB & YAR & DMA & THE & BAY & \\
\hline$?$ & sta.re 'axe' & hta.re & hta.re & hta.rə & hta.ri & rta.ri & rta.ri & 746
\end{tabular}

Table 13: The word sta.re in Amdo dialects

\subsubsection{Abnormal raising of Old Tibetan rhyme -e}

However, open-syllable -e in Old Tibetan does not always give e as expected. Sometimes, it has become $i$ in modern dialects. Several generalizations can be made about the situation in Hua (2002). The phenomenon is absent in verbs, which either indicates its origin as interdialectal borrowing, or points to phonological constraints. Among 11 monosyllabic words, no raised forms are attested. Among 25 polysyllabic words with first-syllable -e and 23 with last-syllable -e, there are 9 and 12 raised forms respectively, showing a bias towards last-syllable raising.

There is a dialectal difference in frequency, where it is absent in BsA and REB, but frequent in the agricultural dialect of YAR ( 9 cases), and the nomad dialects of DMA and The (5 and 4 cases). The count above did not include two cases, that of religious terms like OT mchod.me 'butter lamp' (\#891, $i$ in BSA, REB, YAR and BAY), rdo.rje 'vajra' (\#900, $i$ in all dialects except YAR); and that of cases which I call here $i$-ə-e, exemplified with the word OT sta.re 'axe' (\#746), which shows a surprising number of $i$-reflexes, as is shown in Table 13.

The Them ·chen dialect in Haller (2004), similarly, has stari. Here a hypothesis is proposed that these forms showing $i$ are secondary. The forms with $\partial$ reflects $\mathrm{OT}^{*} s t a \cdot r i^{12}$, the majority form in non-Amdo dialects ${ }^{13}$. As it is probable that $\partial$ is in fact a phonologically high / $\mathbf{i}$ / (discussed in Section 2.5), the forms with $i$ can be considered blends, i.e. interdialectal intermediate forms, sharing the frontness of $e$ and the height of $ә$. A similar case is given by OT snye.ma 'ear (of grain)' (\#491), with $i$-reflex in BsA, YAR and BAY, and $ə$ in REB, where, similarly, three Ngari dialects (Dge-rgyas, Mtsho-chen and Sger.rtse) show forms reflecting an OT $i$.

\footnotetext{
${ }^{12}$ This form does not appear in the Old Tibetan corpus OTDO, where the only form attested is sta.re, as in Pt. 1287 l. 503, sta.re gchig gï dgra 'o '(Even a hundred-year-old pine tree) is fair game for an axe.' The form sta.ri, however, appears in Dag.yig gsar.bsgrigs as a variant, alongside sta.gri, which might lie in the origin of sta.ri.

${ }^{13}$ The eight dialects (Lhasa and seven Ngari dialects) in Qu (1983) all show forms reflecting * sta.ri, mostly tárí. The huge amount of mostly tonal Eastern Tibetan dialects recorded by Suzuki (2009) also shows more ${ }^{\star}$ sta.ri than sta.re. For ease of interpretation, citations from tonal dialects of Tibetan are retranscribed in Africanist tonal notation, as is defined in standard IPA.
} 


\begin{tabular}{ll|ccccccl} 
CA & & BSA & REB & YAR & DMA & THE & BAY & \\
\hline -o & mtsho 'lake' & tsho & tsho & tsho & mtsho & mtsho & tsho & 36 \\
-o & phyi.dro 'afternoon' & ro & ro & ro & ro & ro & ro & 1026 \\
-o & gso 'to rear.Pst' & hso & hso & so & hso & hso & so & 2025
\end{tabular}

Table 14: Modern reflexes of $\mathrm{CA}^{*}{ }^{*} \mathrm{O}$

\subsubsection{Closed rhyme}

In modern Amdo dialects, the vowel quality in closed syllables is akin to that in open syllables, a high and tense cardinal [e]. However, there are some traces of a former lowering: the lowering of ${ }^{\star}$ en, merging with ${ }^{\star}$ an as [æn] in REB and YAR. BAY shows more extensive traces of a lowering: ${ }^{\star}$ ep, et become $\varepsilon$ as ${ }^{\star}$ ap, at, ${ }^{\star}$ en (em), er become [æn], [ær] as *an (am), ar. In BAY, in every former closed syllable ${ }^{\star}$ a merged with ${ }^{\star} e$, giving a sound in between.

\section{$2.4{ }^{\star} \mathrm{O}$}

The Core Amdo rhyme ${ }^{\star}$ o remains unchanged in all Amdo dialects (Table 14). In closed syllables, ${ }^{\star} O$ always has the same quality as in open syllables, a closed [o]. In BAY, on the contrary, ${ }^{\star}$ op, ${ }^{\star}$ ot give an open rhyme with a lowered vowel $\supset$.

\section{$2.5{ }^{*} \boldsymbol{\theta}$}

The Core Amdo vowel ${ }^{\star} \partial$ comes from Old Tibetan vowels $i$ and $u$. It remains $ə$ in all Core Amdo dialects. Although its most frequent allophone is transcribed [ə], the vowel is likely to be phonologically high, better transcribed as $/ \mathbf{i} /$, considering its origin and allophonic behaviour.

Unlike Core Amdo dialects, BAY retains the distinction of the two Old Tibetan vowels, albeit with numerous secondary developments. Even though BAY is not taken into account in the reconstruction of Core Amdo, it sheds important light on the development of Core Amdo dialects, and will be treated here in particular.

I start by the more archaic closed rhymes, proceeding then to open rhymes, where the BAY reflexes depend on the initial. As is shown in Table 15, in Core Amdo dialects, Old Tibetan $i$ and $u$ merge into ${ }^{\star} \partial$. In BAY, on the contrary, $i$ gives ə, while $u$ gives $\theta$.

In open rhymes, four classes of initials need to be distinguished: neutral (velar and $/ \mathrm{n} /$ ), palatal, apical (alveolar and retroflex) and labial. The regular outcome in BAY is shown in Table 16. 


\begin{tabular}{ll|ccccccl} 
CA & & BSA & REB & YAR & DMA & THE & BAY & \\
\hline -ər & btsir 'to squeeze' & tsər & tsər & htsə & ptsər & ptsər & tsər & 1684 \\
-ər & skur 'to send.PRs' & hkər & hkər & hkə & rkər & rkər & hkөr & 1689 \\
-ən & sprin 'cloud' & sən & sən & sən & fən & wtşən & sən & 8 \\
-ən & spun 'siblings' & hpən & sən & hpən & rfən & wsən & hsøn & 298,299 \\
-ət & khrid 'to lead.PsT' & tchəl & cçhəl & tchə & cçhət & tchəl & tchə & 1527,1847 \\
-ət & lud 'manure' & ləl & ləl & lə & lət & ləl & le & 771
\end{tabular}

Table 15: Modern reflexes of $\left.\mathrm{OT}^{\star} i / \mathrm{u}_{(\mathrm{CA}}{ }^{\star} \partial\right)$ in closed syllables

\begin{tabular}{c|cccc} 
OT & neutral & palatal & apical & labial \\
\hline$-i$ & $-{ }^{14}$ & $i / 1$ & 1 & $\partial$ \\
$-u$ & $\partial$ & $y$ & $\Psi$ & $u$
\end{tabular}

Table 16: Regular reflexes in BAY open syllables of OT $-i / u$

After a velar initial, the rhyme $-u$ gives ə: hgə < dgu 'nine' (\#1068); htça. ${ }^{\mathrm{n}} g$ ə $<$ spyang.khu 'wolf' (\#408); mdzə.yə < mdzu.gu 'finger' (\#141), with a regressive assimilation. There are no words with a velar initial and $-i$ rhyme in Hua (2002), however, it is reasonable to suppose that $-u$ and $-i$ merged after a velar initial, as in Core Amdo dialects. Note that an Old Tibetan syllable of form $K u(b / d)$ would have given $\mathrm{Ke}^{15}$, which would have formed a near-minimal pair. The only example with $n-$-, similarly, turns $-u$ into ə: nə.ma $<$ nu.ma 'breast' (\#126).

After a palatal initial, the rhyme $-i$ gives $i$, and $-u$ y: tchy $<$ chu 'water' (\#36, 59); zy < gzhu 'bow' (\#785); t6hy < khyu 'herd' (\#1129); chi < shi 'to die' (\#1931); ji < myi 'human being' (\#205); hni.lan < rmyi.lam 'dream' (\#930). However, after a voiceless palatal affricate, the outcome of OT $-i$ is an apicalized $1^{16}: t \varphi_{1}<$ gri (\#680); htcl $<$ skyi 'to borrow' (\#1722); tch $<$ khyi 'dog' (\#364).

After an apical initial (save $n-),-u$ and $-i$ are respectively apicalized to $-\Psi$ and -1 , examples for which abound: hly $<k l u$ 'nāga' (\#848); tsh $<<$ 'thu 'to collect.PRs' (\#1511, 1694, 2088); ts $<d u$ 'how many' (\#1221); 'dzY < 'bru 'cereals' (\#488); zl $<$ gzi 'onyx' (\#75); hla.hts $<$ gla.rtsi 'musk' (\#397).

After a labial initial, $-u$ gives $u$ : hnək.pu $<(d) m y i g \cdot s p u$ 'eyebrow, eyelash'

\footnotetext{
${ }^{14}$ One anonymous reviewer raised the question whether all the reflexes are contrasting phonemes. Except for the $y \sim \mathcal{Y}$ pair, the evidence is positive, compare khi $<$ mkhas (\#1390), khl < 'khel (\#1505, \#1790); hdzay.kho < ljang khu (\#1277); lo < lud (\#1757), lq < lus (\#1770).

${ }^{15} \mathrm{~K}$ is for any velar initial. Unfortunately, the only example of this form, OT ras.skud 'thread' (\#573), has an unexpected form ri.hkək in BAY, but note for example hken.ma < rkun.ma 'thief' (\#244).

${ }^{16}$ Both the term apical vowels and the symbols 1, $y$ belong to the descriptive tradition of Chinese and languages in the same area. They are syllable alveolar approximants: $/ \mathrm{l}=[\mathrm{z}] ; / \mathrm{\Psi} /=\left[\mathrm{z}^{\mathrm{w}}\right]$.
} 
(\#108, 109); wu.tsa cf. OT bu 'son' (\#283); 'bu < 'bu 'insect, worm' (\#435). Only one morpheme with a labial initial and $-i$ exists in the materials: the negative prefix mə $<m i(\# 2101)$.

In conclusion, a previous stage of open rhymes can be reconstructed as identical to closed rhymes: $\boldsymbol{\partial}$ for $-i$, and $\boldsymbol{\theta}$ for $-u$. In open rhymes, $\boldsymbol{\theta}$ preserves its labial feature if it changes into a different rhyme ( $y$, ч or $u$ ) by dint of the initial; otherwise, it has merged with $\partial<-i$.

There remains two issues about the development of what corresponds to Core Amdo ${ }^{*} \partial$ in BAY. First, in disyllables, some first-syllable open $-u$ and $-i$ remains $-\theta$ and -ə, as in closed rhymes: thhə.mo $<$ khyi.mo 'bitch' (\#365) besides tchl $<k h y i$ 'dog' (\#364); hdzө.ma < rgyu.ma 'intestine' (\#186); høə. "go < dpyi.mgo 'hipbone' (\#189). I hypothesize that originally, only second-syllable $-\theta$ and $-\partial$ underwent the change into other rhymes. The other cases of first-syllable changed rhymes are due to reanalysis of compounds.

Second, a labial preinitial $(m-, b-)$ in Old Tibetan sometimes influences the vowel quality of the reflex of $i$, making the vowel sounding like OT $u$ (Zhang, 2009): zy < bzhi 'four' (\#1063); t6hen.ba < mchin.pa 'liver' (\#181). This effect should be considered secondary, considering the fact that in BAY and other dialects, such preinitials often induce a labialization on the following consonant: BAy khwar, THE mkhwar < mkhar 'fortified city, castle' (\#97).

\section{$2.6{ }^{*} \mathbf{i},{ }^{\star} \mathbf{y},{ }^{\star} \mathbf{I},{ }^{\star} \mathbf{Y}$}

This subsection discusses the rhymes which, among other possible origins, come from Old Tibetan rhymes with a coda $-s$ (Table 17). All these rhymes become $i$ in THE. Additionally the Old Tibetan rhymes $i l, e l, e^{\prime} u$ give the same reflexes as is in all the Amdo dialects surveyed.

In YAR and BAY, both agricultural dialects heavily influenced by Chinese, Core Amdo high front vowels are apicalized under certain conditions. The apicalized vowels are transcribed $/ \mathrm{Y} /\left(\left[\mathrm{z}^{\mathrm{w}}\right]\right)$ when rounded and $/ \mathrm{l} /([\mathrm{z}])$ when not. In both dialects, it is the case after apical consonants. Additionally, in BAY, all non-palatal initials cause apicalization: $k h_{1}<$ 'khel 'to hit (the target)' (\#1505), cf. BsA, REB, YAR, THE khi.

In THE, a labialized consonant or a $w$ lowers a following $i$ to $e$, as is seen with the word * brel (OT drel) 'mule' (\#356) in the examples. Compare li < lus "to be lost" (\#1770) with wkwe < brkus "to steal.PsT" (\#1963).

With these secondary developments in mind, the forms in the five Core Amdo dialects can be reduced to three types. We reconstruct four Core Amdo rhymes for the rhymes concerned in this subsection: ${ }^{\star} i,{ }^{\star} I,{ }^{*} y,{ }^{\star} Y$. Concerning their origins, ${ }^{\star} \mathrm{i}<\mathrm{OT}$ is, il, el; ${ }^{\star} \mathrm{y}<\mathrm{OT} u s ;{ }^{\star} \mathrm{I}<$ as, es; ${ }^{\star} \mathrm{Y}<$ os. The three types of de- 


\begin{tabular}{|c|c|c|c|c|c|c|c|c|}
\hline \multicolumn{2}{|c|}{ CA } & BSA & REB & YAR & DMA & THE & \multicolumn{2}{|l|}{ BAY } \\
\hline$-i$ & dris 'to ask.PST' & tşi & tşi & ts1 & tşi & tşi & tş & 1983 \\
\hline$-\mathbf{i}$ & *brel 'mule' & tsi & tşi & ts1 & ptsi & ptswe & tsૅ & 356 \\
\hline$-\mathrm{i}$ & tshil 'fat' & tshi & tshi & $\mathrm{tsh}$ & tshi & tshi & tsh1 & 543 \\
\hline$-i$ & the'u 'seal' & thi & thi & $\mathrm{tsh}$ & thi & thi & $\operatorname{tsh} 1$ & 739 \\
\hline$-\mathrm{y}$ & lus 'to be lost' & li & li & 1 & lu & li & $1 ૫$ & 1770 \\
\hline$-I$ & nas 'barley' & ne & ne & ne & ni & ni & ni & 497 \\
\hline$-\mathrm{I}$ & bzhes 'to take.HON' & ze & ze & ze & wzi & wzi & zwi & 1483 \\
\hline$-Y$ & $z o s$ 'to eat.PsT' & se & se & se & $\mathrm{zu}$ & si & swi & 1471 \\
\hline & Type & $\mathrm{e}$ & e & $\mathrm{e}$ & $\mathrm{u}$ & $\mathrm{i}$ & we & \\
\hline
\end{tabular}

Table 17: Modern reflexes of Core Amdo rhymes ${ }^{\star}-i,{ }^{\star}-y,{ }^{\star}-I$ and ${ }^{\star}-Y$.

velopments, conveniently labeled with the reflex of ${ }^{{ }^{*}} Y(<$ OT os $)$, are listed as follows:

- i-type: all four rhymes giving i. (ThE, Them·chen (Haller, 2004), Rtse-khog (Qu, 1991))

- e-type: ${ }^{\star} i, y$ gives $i,{ }^{\star} I, Y$ gives e same as ${ }^{\star} e$. (BsA, REB, YAR)

- $u$-type: ${ }^{\star} i$, I gives $i,{ }^{\star} y, y$ gives u same as ${ }^{\star} u$. (DMA, Mdzod·dge (Sun, 1986), rMa.chu (Zhoumaocao, 2004), A.rig $(\mathrm{Qu}, 1991))^{17}$

As is mentioned for $\mathrm{CA}^{\star} e$ (2.3.2), forms which regularly will give e in modern dialects sometimes actually gives $i$. Similarly, in BAY, ${ }^{\star} I, Y$ regularly give rise to $i$, $y$, which differs from ${ }^{*} i$, $y$ by the lack of apicalization: BAY ${ }^{n} d z i<$ OT 'bras 'rice' (\#489), cf. tş < OT brel 'busy' (\#1351). (Note the effect of the labialized initial br-.)

Hence, BAY in fact belongs to a sui generis we-type, similar to e-type in that ${ }^{*} I$ and ${ }^{*} e$ have identical reflexes. The difference between BAY and e type is that the difference between all four Core Amdo rhymes are reflected in BAY, with the rounded rhymes being reflected by a $-W$-. Another minor type is represented by Suǒlā (所拉) dialect in Dkar-mdzes (Qu, 1991). In this dialect, ${ }^{\star} Y$ is reflected as $u$, while ${ }^{\star} y$ remains ${ }^{*} y .{ }^{18}$ The extreme diversity, compared to the general closeness of Amdo dialects, points to a late date of the collapse of the four-vowel system in modern-day dialects.

\footnotetext{
${ }^{17}$ For a historical parallel to the sound change $u<y$, the same thing happened in the dialect of Modern Greek known as Old Athenian (Newton, 1972), where the late koiné vowel *y $(<\mathrm{u}$, ol) merged with *u (< ov) to give a modern $u$ : Megarian (Old Athenian) ju'neka $<{ }^{*} y^{\prime} n e k a<$ үuvaĩka 'woman' (from the old accusative) (p.21).

${ }^{18} \mathrm{Qu}(1991)$ did not state precisely the behaviour of ${ }^{\star} i$ and ${ }^{\star} I$, but it could be presumed that they are both reflected as $i$.
} 


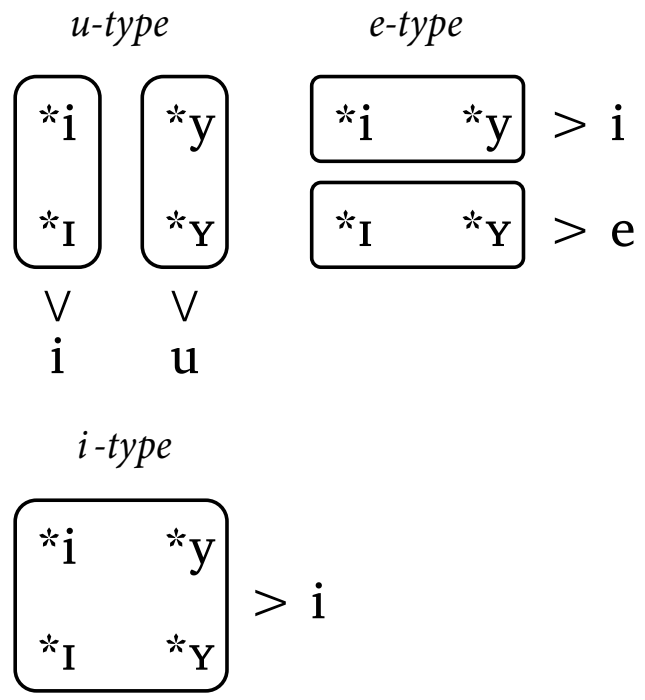

Figure 3: Major types of outcome for Old Tibetan rhymes in -s

\begin{tabular}{ll|lllllll} 
CA & & BSA & REB & YAR & DMA & THE & BAY & \\
\hline CA & & BSA & REB & YAR & DMA & THE & BAY & \\
$-\mathrm{u}$ & skol 'to boil.pRs' & hku & hku & hku & rku & rku & hku & 1401 \\
$-\mathrm{u}$ & $\begin{array}{l}\text { dngul 'silver' } \\
-\mathrm{u}\end{array}$ tsha.bo 'nephew, grandson' & hyu & hyu & hyu & ryu & ryu & hyu & 67 \\
& tshu & tshu & tshu & tshu & tshu & 287,297
\end{tabular}

Table 18: Modern reflexes of $\mathrm{CA}^{*}-\mathrm{u}$

\section{$2.7{ }^{\star} \mathbf{u}$}

The Core Amdo vowel ${ }^{\star} u$ remains $u$ in all the dialects concerned. It has three OT origins: $o l, u l$ and merged dissyllables ending in $a \cdot b o, o \cdot b o$ or $u \cdot b o$.

For -o.bo, see for example Mdzod.dge (Sun, 1986) ku < OT go.bo 'vulture'. For $-u \cdot b o$, the only examples are words of kinship: THE hu $<$ OT phu.bo 'elder brother', BAY nu < OT nu.bo 'younger brother'.

\section{$2.8{ }^{\star} a$}

The Core Amdo vowel ${ }^{\star} a$ (Table 19) merged with ${ }^{\star} a$ in all the dialects described in Hua (2002) but DMA. The distinction between ${ }^{\star} a$ and ${ }^{\star} a$ is also preserved in Mdzod.dge (Sun, 1986) as /a/ (for CA*a) versus /æ/ (for CA*a). The distinction is present in the speech of elder speakers in Labrang town, too, lest it be considered 


\begin{tabular}{ll|ccccccc} 
CA & & BSA & REB & YAR & DMA & THE & BAY & \\
\hline CA & & BSA & REB & YAR & DMA & THE & BAY & \\
-a & $b a l$ 'wool' & wa & wa & wa & wa & wa & wa & 354 \\
-a & $r a \cdot b a$ 'fence' & ra & ra & ra & ra & ra & ra & 647
\end{tabular}

Table 19: Modern reflexes of $C^{*}{ }^{*}-a$

a southeastern-only phenomenon (Gesang-Jumian and Gesang-Yangjin, 2002). It has two Old Tibetan origins: $-a l$ and $-a \cdot b a$.

There are two cases where the Old/Written Tibetan equivalent of a disyllabic word has an open - $a$ rhyme, but the corresponding DMA form shows [a]: vowel harmony and recomposition.

The first process, vowel harmony, is also present in Mdzod.dge, where it is subject to a rigorous analysis in Sun (1986, p.73-84). According to Sun, this process applies only to a disyllabic word, where $/ æ /\left(<\mathrm{CA}{ }^{\star} \mathrm{a}\right), / \mathrm{e} /$ and $/ \mathrm{o} /$, as the vowel of the first syllable, are respectively lowered into $/ \mathrm{a} /(<a), / \varepsilon /$ and $/ \mathrm{s} /$, if one of the following conditions hold:

- The second syllable contains the vowel $/ \gamma /\left(<\mathrm{CA}{ }^{\star} \partial\right), / \mathrm{u} /$ or $/ \mathrm{i} /$ (called dominant vowels by Sun): tom 'bear' and $t s^{h} \gamma g$ 'youngling' are composed to make tomts ${ }^{h} \gamma g$ 'bear cub' > [tomts $\left.{ }^{\text {h }} \gamma \gamma\right]$.

- The second syllable consists of the nucleus /a/ or /o/ and a velar coda. In other words, the second syllable is of rhyme -ay, -oy, -ag or -og: ser 'gold'

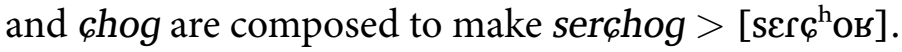

- Only when the first syllable nucleus is æ, a vowel /a/ in the second syllable assimilates the æ to a:

In DMA, /a/ in the first syllable of a disyllabic word changes into [a] when the second syllable:

- contains the vowel $/ \partial /, / \mathrm{u} /$ or $/ \mathrm{i} /$, ex. ra.lək $<$ ra.lug 'goats and camels' (\#348), rna.ptcə < lnga.bcu 'fifty' (\#1087), ptsa.chi < bkra.shis 'auspiciousness' (\#923), ka.rju 'bowl' < dkar.yol (\#685);

- is of rhyme -ay, -oy or -ak, ex. w6a.tshay < bya.tshang 'birds' nest' (\#412), rya.mon < rnga.mong 'camel' (\#358), xha.nak < sha.snag 'lean meat' (\#540).

- When the second syllable has the nucleus a: rta.ra $<$ rta.ra(.ba) 'horse corral' (\#628).

Not all DMA forms noted in Hua (2002) show effects of vowel harmony: rna.khon $<$ sna.khung 'nostril', rma.xhu < rma.shul 'scar'. Despite examples like this, it is 


\begin{tabular}{|c|c|c|c|c|c|c|c|c|}
\hline CA & & BSA & REB & YAR & DMA & THE & BAY & \\
\hline-3 & $d u \cdot b a$ 'smoke' & to & to & tə.wa & to & to & to.wa & 20,564 \\
\hline כ & $k h u \cdot b a$ 'soup' & khə & kho & khu.wa & kho & kho & kho.wa & 560 \\
\hline -כ & pho.ba 'stomach' & ho $\sim$ ho.wa & ho & - & ho & ho & ho.wa & 128,185 \\
\hline כ- & $d g o \cdot b a$ 'antelope' & hgo & hgo & hgo & rgo & rgo & hgo.wa & 395 \\
\hline -כ & $m c h e \cdot b a$ 'fang' & tcho & cçho & - & mtcha & mtcho & tcho.wa & 172 \\
\hline$-\varepsilon$ & lji.ba 'flea' & hdze & ze & hdze & rdzo & rdze & hdze.a & 437 \\
\hline$-\varepsilon$ & $l c i \cdot b a$ 'dung' & htce & htce & ht $6 \varepsilon$ & ht6o & rtce & hyia & 333 \\
\hline$-\varepsilon$ & lte.ba 'navel' & hte & ht $\varepsilon$ & hte & rte & rte & hte.a & 129 \\
\hline$-\varepsilon$ & sme.ba 'mole' & $\mathrm{hm} \varepsilon$ & $\mathrm{hm} \varepsilon$ & hman & - & rme & hmia & 156 \\
\hline
\end{tabular}

Table 20: Modern reflexes of $\mathrm{CA}^{*}-\mathcal{\varepsilon},{ }^{*}-\supset$

likely that the process is automatic in DMA, just as in Mdzod.dge, as, for a phonetic process, it is left to the transcriber's own choice whether to transcribe it. Cases like this are reconstructed as ${ }^{\star} a$, as I take the vowel harmony as secondary.

The second case of apparent OT $a-\mathrm{CA}^{\star} a$ correspondence involves recomposition, which can be illustrated with compounds from the word OT raba 'enclosure'. Gardens, for example, are enclosures of plants (OT ldum(.bu)). In Old Tibetan, a language which prefers disyllabic nouns, only the root $r a$ enters the compound form: ldum.ra (Pt. 1085 l. r3, 7). In Core Amdo, ra.ba has already fused into ${ }^{\star} r a$, which can directly enter disyllabic compounds. Speakers conscious of the derivation will change the second syllable from ${ }^{\star}$ ra to ${ }^{\star}$ ra for better transparency, giving DMA rdəm.ra (\#648). This a should be reconstructed at the level of Core Amdo.

\section{$2.9{ }^{\star} 0,{ }^{\star} \varepsilon$}

These rhymes come from Old Tibetan disyllables, $i \cdot b a, u \cdot b a, e \cdot b a$ and $o \cdot b a$ (Table 20). They are put in the last place, because there are difficulties with the reconstructions, which remain for now tentative.

As can be seen in Table 20, the modern reflexes involved are quite irregular. There are two patterns, however, that emerge from this irregularity:

First, YAR often shows non-fusional forms where other Core Amdo dialects show it. This can be attributed to a later layer of loans from a BAY-like dialect, as names of tools, for example, all show non-fusional forms: so.wa $<$ OT $z o \cdot b a$ 'bucket' (\#695, cf. DMA ţhə.zJ), jo.wa < OT yu.ba 'handle' (\#767, cf. DMA jJ).

Second, there is a systematic difference between the lexical set lji.ba, lci.ba, on the one hand, and lte.ba, sme.ba on the other. The first group shows e in REB and $o$ in DMA; the second shows $\varepsilon$ in ReB and e in DMA. The nature of the distinction 
is unclear, due to the paucity of the data: the first group always has palatal initials and the second always non-palatal; however, the first group come from OT $-i \cdot b a$ etymologically and the second from $e \cdot b a$. The first reason implies that the given reconstruction as ${ }^{\star} \mathcal{E}$ is reasonable, while the second implies two fusional vowels, maybe ${ }^{\star} \varnothing$ from $-i \cdot b a$ and ${ }^{\star} \varepsilon$ from $-e \cdot b a$.

Mdzod.dge Tibetan Sun (1986) shows a more regular derivation: always $-\boldsymbol{\supset}<$ $-u \cdot b a,-o \cdot b a ; \varepsilon<-i \cdot b a,-e \cdot b a$. While further research is needed, with fresh data, a preliminary reconstruction is offered here, the same as in Mdzod.dge.

\subsection{Conclusion}

Now I will recapitulate the characteristic sound changes from Core Amdo to individual Amdo dialects.

- For BsA, ${ }^{\star} a$ merged with ${ }^{\star} a,{ }^{\star} \varepsilon$ with ${ }^{\star} e$, but ${ }^{\star} \supset$ remained ${ }^{\star} \supset$. Vowels from OT coda -s shows e-type reflexes: ${ }^{\star} I, Y>e={ }^{\star} e,{ }^{\star} i, y>i$. Codas are preserved intact.

- For REB, ${ }^{\star} a$ merged with ${ }^{\star} a,{ }^{\star} \supset$ with ${ }^{\star} o$, but ${ }^{\star} \varepsilon$ seems to be preserved as ${ }^{\star} \varepsilon$. Vowels from OT coda $-s$ show e-type reflexes. All codas are preserved intact, except for ${ }^{\star} e t$, ot which gives $e={ }^{\star} e$ and $\emptyset$.

- For YAR, there is one case of preservation of $\varepsilon$, otherwise ${ }^{\star} a, \jmath, \varepsilon$ gives ${ }^{\star} a, o$, e. Vowels from OT coda $-s$ show e-type reflexes. Codas ${ }^{\star}-p,-t,-r$ are lost, changing a main vowel ${ }^{\star} a$ to a phonologizes $\varepsilon$. Coda ${ }^{\star} m$ merged with ${ }^{\star} n$. In an open syllable, a modern $i$ is apicalized after an apical initial.

- For DMA, ${ }^{\star} a$ is preserved, no doubt helped by the fact that ${ }^{*}$ a raised to near [æ]. ${ }^{\star} \supset$ is similarly preserved, while ${ }^{\star} \varepsilon$ goes to [e] (however, some words show [o], a point which needs further investigation). Vowels from OT coda -s show $u$-type reflexes: ${ }^{\star} y, y>u={ }^{\star} u,{ }^{\star} i, I>i$. Codas are preserved intact.

- For The, ${ }^{\star} a$, o, $\varepsilon$ merged with ${ }^{\star} a, o$, e. Vowels from OT coda $-s$ show $i$ type reflexes: ${ }^{\star} i, I, y, Y>i$. Codas are preserved intact. Additionally, what would have become wi gives we, in a secondary lowering.

BAY, which lies outside the reconstruction scope of Core Amdo, shows two major archaisms not reconstructed for Core Amdo: non-fusion of OT $V \cdot p a, V \cdot b a$ structures, and non-merger of OT $i$ and $u$. The high vowels $i$ and $u$ are centralized to $\boldsymbol{\theta}$ and $\partial$, precursors to the Core Amdo merged forms. In final rhymes corresponding to Core Amdo open rhymes, $\boldsymbol{\theta}$ and $\boldsymbol{\partial}$ underwent secondary changes, according to the place of articulation of the initial. 


\begin{tabular}{|c|c|}
\hline Rhyme & Old Tibetan origin \\
\hline${ }^{*}-a$ & $-a$ \\
\hline${ }^{\star}-a k$ & $-a g,-e g$ \\
\hline *-ay & -ang, -eng, -ing \\
\hline${ }^{*}-\mathrm{aC}$ & $-a C$ \\
\hline${ }^{*}-e$ & $-e$ \\
\hline *-eC & $-e C$ \\
\hline$*_{-O}$ & $-O$ \\
\hline${ }^{*}-\mathrm{oC}$ & $-o C$ \\
\hline${ }^{*}$-ok & $-o g$ \\
\hline *-on & -ong, -ung \\
\hline *-ว & $-i,-u$ \\
\hline${ }^{*}-\partial C$ & $-i C,-u C$ \\
\hline *-ək & $-i g,-u g$ \\
\hline${ }^{\star}-i$ & $-i s,-i l,-e l$ \\
\hline${ }^{*}-y$ & $-u s$ \\
\hline$*_{-I}$ & $-a s,-e s$ \\
\hline${ }^{*}-Y$ & $-o s$ \\
\hline$\star^{*}-u$ & $-u l,-o l,-a \cdot b o,-o \cdot b o,-u \cdot b o$ \\
\hline${ }^{*}-a$ & $-a l,-a \cdot b a$ \\
\hline *-כ & $-u \cdot b a,-o \cdot b a$ \\
\hline${ }^{\star}-\varepsilon(?)$ & $-i \cdot b a,-e \cdot b a$ \\
\hline
\end{tabular}

Table 21: Old Tibetan origins of Amdo Tibetan rhymes

Concerning the vowels from Old Tibetan coda $-s$, BAY shows a conservative type: ${ }^{*} i>i,{ }^{*} y>w i \sim y,{ }^{*} I>e={ }^{\star} e,{ }^{*} Y>w e \sim \emptyset$. Then, ${ }^{\star} I, Y$ raised together with ${ }^{\star} e$ to become $i, y$, with the difference that apicalization is not possible with rhymes of this origin.

In BAY, ${ }^{\star} a$ merged with ${ }^{\star} a$, codas ${ }^{\star}-p$, $-t$ are lost, merging ${ }^{\star} a$ and ${ }^{\star} e$ to $\varepsilon$ and lowering ${ }^{\star} o$ to . . Coda ${ }^{\star}$-m merged with ${ }^{\star}$-n.

The Old Tibetan origin of Core Amdo rhymes are capitulated in Table 21. To avoid cluttering, $C$ stands for $m, n, r, p$ and $t$, the latter two written $b$ and $d$ in Tibetan orthography. Also, as OT post-final $-s,-d$ are systematically disregarded in rhymes ${ }^{19}$, they are not mentioned in the table.

\footnotetext{
${ }^{19}$ A post-final $-s$ sometimes leads to an initial cluster on a following - $p a$ (Sun, 1986, p. 143):






\section{Vowel length in pre-Core Amdo}

Core Amdo has 12 vowels, a large number, especially when compared with its five-voweled ancestor, Old Tibetan. This is an unstable system, which then collapsed into a 6-voweled system in an innovating dialect like THE. The question is to explain how such a complex system could come into being in the first place.

Note that the 12 vowels of Core Amdo naturally fall into two classes: those which can take a coda and those which cannot. The first class comprises ${ }^{\star} a,{ }^{\star} \partial$, ${ }^{\star} e$ and ${ }^{\star} O$; the second class comprises ${ }^{\star} a,{ }^{*} i,{ }^{\star} u,{ }^{\star} I,{ }^{*} y,{ }^{\star} Y,{ }^{\star} \varepsilon$ and ${ }^{\star} \mathrm{J}$. There are profound differences between these two classes of vowels, both diachronically and synchronically.

Diachronically, vowels of the first class always correspond to Old Tibetan vowels: they occur in closed syllables when the etymon has a coda, and in open syllables when the etymon does not. Those of the second class, however, either come from Old Tibetan rhymes with a disappeared coda $(\mathrm{V}<\mathrm{VC})$, or coalesced Old Tibetan disyllables $(\mathrm{V}<\mathrm{VCV}):{ }^{\star} a(a l, a \cdot b a),{ }^{*} \mathrm{i}(i l, e l, i s),{ }^{*} u(u l, o l, a \cdot b o, o \cdot b o),{ }^{\star} I$ $(a s, e s),{ }^{\star} y(u s), / \mathrm{Y} /(o s),{ }^{\star} \mathcal{E}(i \cdot b a, e \cdot b a),{ }^{\star} \mathrm{J}(u \cdot b a, o \cdot b a)$.

Synchronically, in conservative dialects where the reflexes of the two classes are kept distinct, like Mdzod.dge (Sun, 1986, p.88), the two classes of vowels exhibit drastically different morphological behaviour. In Mdzod.dge, the genitive/ ergative case of a noun is constructed either with ablaut or suffixation. Ablaut applies only to nouns where the final syllable is an open syllable containing reflexes of the first class of vowels: /æ/ $\left(<\mathrm{CA}^{\star} \mathrm{a}\right), / \mathrm{e} / \mathrm{,} / \mathrm{o} / \mathrm{or} / \gamma /\left(<{ }^{\star} \partial\right)$; suffixation applies to closed syllables and open syllables with the second class of vowels: /a/ $\left(<\mathrm{CA}{ }^{\star} a\right), / \mathrm{i} /\left(<{ }^{\star} i,{ }^{\star} I\right), / \mathrm{u} /\left(<{ }^{\star} \mathrm{u},{ }^{\star} y,{ }^{\star} \mathrm{Y}\right), / \varepsilon /$ or $/ \mathrm{J} /$.

The key to the distinction lies in the vowel /a/. How can its two etymons, al and $a \cdot b a$ result in the same rhyme? Two hypotheses can be formed in principle:

- $a l>$ /a:/, a.ba /awa/ > /a:/; then /a:/ > /a/.

- $a l>/ \mathrm{al}^{\mathrm{Y}} />/ \mathrm{aw} /, a \cdot b a>/ \mathrm{aw} /$; then $/ \mathrm{aw} />/ \mathrm{p} />/ \mathrm{a} /$.

The first hypothesis is to be prefered. If $a \cdot b a$ gave /aw/ as per the second hypothesis, $u \cdot b a$ would have given /uw/, a long way from the desired reflex ${ }^{\star}$. More pertinently, the intermediate step of the first hypothesis is identical to actually attested situations in tonal dialects of Tibetan, such as Shigatse (Haller, 2000; Gesang-Jumian and Gesang-Yangjin, 2002). In Shigatse Tibetan, both OT al and $a \cdot b a$ have become /a:/: cáá $<$ OT sha ba 'deer', phàá $<$ bal 'wool'.

Now that it has been determined that ${ }^{\star} a</ a$ :/, the other vowels in the second class also come from long vowels: ${ }^{\star} i$ and ${ }^{\star} u$, as Vl $>\mathrm{VV} ;{ }^{\star} i$ also comes from is so ${ }^{\star} I,{ }^{\star} Y,{ }^{\star} y$ should have similar origins; as for ${ }^{\star} \varepsilon$ and ${ }^{\star}$ ? , they should also be 


\begin{tabular}{l|l|l} 
1st class & \multicolumn{2}{|c}{ 2nd class } \\
\hline $\mathrm{a}<\mathrm{a}$ & $\mathrm{a}<\mathrm{a}:$ & $\mathrm{y}<\mathrm{y:}$ \\
$\mathrm{e}<\mathrm{e}$ & $\mathrm{i}<\mathrm{i}:$ & $\varepsilon<\mathrm{\varepsilon :}$ \\
$\mathrm{o}<\mathrm{o}$ & $\mathrm{u}<\mathrm{u:}$ & $\mathrm{\jmath}<\mathrm{\jmath :}$ \\
ə $<$ ə & I $<\mathrm{e:}$ & $\mathrm{y}<\varnothing:$
\end{tabular}

Table 22: Reconstruction of pre-Core-Amdo vowels

considered as coming from long vowels, in order to explain the shared properties of the second class.

Thus, the older forms of Core Amdo vowels can be reconstructed as is shown in Table 22. Note ${ }^{\star} I</$ e: $/$ and ${ }^{\star} Y</ \varnothing: /$. It is not necessary to reconstruct an additional degree of height in a vowel system that distinguishes length.

\section{Evolution of Amdo Tibetan rhymes}

\subsection{Phonological history of Amdo Tibetan rhymes}

The phonetic evolution of a language is usually analyzable as a series of atomic changes, or sound laws. These changes occur in a relative chronology which can be partially reconstructed by internal means. We can know that one change necessarily comes before another, because, in the terms of generative phonology, one rule feeds another (its outcome fits the prerequisites for the other) or bleeds another (it changes something that could have been the input for the other), so that different orders of the changes do not give the same result. However, the requirements of chronological precedences do not form a total order: between two rules which are not related (transitively) by feeding or bleeding, one cannot tell which one happens first in the language. For ease of presentation, I will first introduce the changes in one plausible chronology, and a graph representing these precedence requirements will be given afterwards. Finally, I will discuss the external evidence that permits a more accurate relative or absolute dating of the changes.

Postfinal $-s$ could have been lost at any stage of the evolution, so it is systematically disregarded in the following account.

We start first from a literal reconstruction ${ }^{20}$ of Old Tibetan, as Stage 0 (Table 23).

The merger of velar rhymes is likely to be early, as it is attested in dialects that do not display other Amdo sound changes, like Khalong Tibetan (Sun, 2007), or

\footnotetext{
${ }^{20}$ However, $b$ in suffixes are supposed, following Jackson T.-S. Sun, to be originally /w/.
} 


\begin{tabular}{c|cccccccccccc} 
& $\varnothing$ & b & d & g & m & n & ng & r & l & s & -ba & -bo \\
\hline a & a & ap & at & ak & am & an & ay & ar & al & as & awa & awo \\
i & i & ip & it & ik & im & in & in & ir & il & is & iwa & \\
u & u & up & ut & uk & um & un & uy & ur & ul & us & uwa & \\
e & e & ep & et & ek & em & en & ey & er & el & es & ewa & \\
o & o & op & ot & ok & om & on & oy & or & ol & os & owa & owo
\end{tabular}

Table 23: Old Tibetan (Stage 0)

one of the source dialects of Tibetan loans in Japhug Rgyalrong (Jacques, 2004). They take us to Stage 1 (Table 24).

Change 1 (/y/-Merger) /V[ + round $] \mathrm{y} /$ sequences become /oy/; /V[-round $] \mathrm{y} /$ sequences become /ay/;

Change 2 (/k/-Merger) /ek/ becomes /ak/.

\begin{tabular}{c|cccccccccccc} 
& $\varnothing$ & b & d & g & m & n & ng & r & l & s & -ba & -bo \\
\hline a & a & ap & at & ak & am & an & ay & ar & al & as & awa & awo \\
i & i & ip & it & ik & im & in & aj & ir & il & is & iwa & \\
u & u & up & ut & uk & um & un & oy & ur & ul & us & uwa & \\
e & e & ep & et & ak & em & en & ay & er & el & es & ewa & \\
o & o & op & ot & ok & om & on & oy & or & ol & os & owa & owo
\end{tabular}

Table 24: After velar mergers (Stage 1)

Long vowels in Amdo originate in the following two sound changes, which take us to Stage 2 (Table 25).

Change 3 (Shigatse-/-1/-Loss) Coda/-1/ disappears, with compensatory lengthening of the vowel ${ }^{21}$

Change 4 (Falling-Contraction) $A / \mathrm{VwV} /$ sequence of falling or identical vowel sonority ${ }^{22}$ coalesces into a long vowel.

\footnotetext{
${ }^{21}$ This sound change is so labeled in a preliminary attempt at a classification of the outcome of OT coda $-l$ in Tibetan dialects into three types all attested in Central Tibetan dialects: retention, as in Sgar (Ngari) pàl < OT bal 'wool'; loss, lengthening and fronting, as in Lhasa phèć; loss and lengthening without fronting, as in Shigatse phàá (Qu, 1983; Haller, 2000).

${ }^{22}$ Here, following most authors, sonority of vowels are taken to correlate with their aperture, or inversely with their height.
} 
The kinship terms ${ }^{\star}$ nu $<$ OT nu.bo 'younger brother' $(\# 291)$ and ${ }^{\star}$ phu $<$ phu.bo 'older brother' (\#289) are understood as already having undergone an irregular assimilation ${ }^{\star} \mathrm{CoCo}<{ }^{\star} \mathrm{CuCo}$, cf. YAR, BAY o.mo $<$ bu.mo 'daughter' (\#285). Hence ${ }^{\star}$ nu $<{ }^{\star}$ no.wo $<$ OT nu.bo.

\begin{tabular}{c|cccccccccccc} 
& $\varnothing$ & b & d & g & m & n & ng & r & l & s & -ba & -bo \\
\hline a & a & ap & at & ak & am & an & ay & ar & a: & as & a: & o: \\
i & i & ip & it & ik & im & in & ay & ir & i: & is & iwa & \\
u & u & up & ut & uk & um & un & oy & ur & u: & us & uwa & \\
e & e & ep & et & ak & em & en & ay & er & e: & es & ewa & \\
o & o & op & ot & ok & om & on & oy & or & o: & os & owa & o:
\end{tabular}

Table 25: Birth of long vowels (Stage 2)

Afterwards, these primary long vowels are raised, giving Stage 3 (Table 26).

Change 5 (Mid-Long-Raising) Mid long vowels are raised to their high counterparts.

Mid-Long-Raising is necessarily preceded by Shigatse-/-1/-Loss and FallingContraction, as it is fed by those two sound changes.

\begin{tabular}{c|cccccccccccc} 
& $\varnothing$ & b & d & g & m & n & ng & r & l & s & -ba & -bo \\
\hline a & a & ap & at & ak & am & an & ay & ar & a: & as & a: & u: \\
i & i & ip & it & ik & im & in & ay & ir & i: & is & iwa & \\
u & u & up & ut & uk & um & un & oy & ur & u: & us & uwa & \\
e & e & ep & et & ak & em & en & ay & er & i: & es & ewa & \\
o & o & op & ot & ok & om & on & oy & or & u: & os & owa & u:
\end{tabular}

Table 26: After Mid-Long-Raising (Stage 3)

A new set of long vowels appeared, from /Vs/ sequences and rising diphthongs, giving Stage 4 (Table 27).

Change 6 (/s/-Loss) Coda /-s/ disappears, with compensatory lengthening and fronting of the vowel. /a/ is fronted as /e:/.

Change 7 (Rising-Contraction) $A / \mathrm{VwV} /$ sequence of rising vowel sonority coalesces into a mid-low long vowel sharing the frontness and roundness of the original. 


\begin{tabular}{c|cccccccccccc} 
& $\varnothing$ & b & d & g & m & n & ng & r & l & s & -ba & -bo \\
\hline a & a & ap & at & ak & am & an & ay & ar & a: & e: & a: & u: \\
i & i & ip & it & ik & im & in & ay & ir & i: & i: & $\varepsilon:$ & \\
u & u & up & ut & uk & um & un & oy & ur & u: & y: & o: & \\
e & e & ep & et & ak & em & en & ay & er & i: & e: & $\varepsilon:$ & \\
o & o & op & ot & ok & om & on & oy & or & u: & ø: & o: & u:
\end{tabular}

Table 27: New long vowels (Stage 4)

/s/-Loss is necessarily preceded by Mid-Long-Raising, as /s/-Loss feeds MidLong-Raising, but doesn't show its effects.

The short high vowels are merged, which marks the passage into Stage 5 (Table 28).

Change 8 (Short-High-Merger) The short high vowels $/ \mathrm{i} /$ and $/ \mathrm{u} /$ merges into /ə/.

Short-High-Merger is necessarily preceded by /s/-Loss and Rising-Contraction, as it bleeds the latter two changes, which, on the contrary, do not show its effects. Similarly, it is necessarily preceded by /n/-Merger.

\begin{tabular}{|c|c|c|c|c|c|c|c|c|c|c|c|c|}
\hline & $\varnothing$ & b & $\mathrm{d}$ & $\mathrm{g}$ & $\mathrm{m}$ & $\mathrm{n}$ & $\mathrm{ng}$ & $r$ & 1 & $\mathrm{~S}$ & -ba & -bo \\
\hline a & $\mathrm{a}$ & ap & at & $\mathrm{ak}$ & $\mathrm{am}$ & an & an & ar & a: & e: & a: & $\mathrm{u}:$ \\
\hline i & $\partial$ & әр & $\partial t$ & ək & әm & ən & an & $\partial r$ & i: & i: & $\mathcal{E}:$ & \\
\hline $\mathrm{u}$ & $\partial$ & әр & zt & ək & әे & ən & oy & ər & u: & y: & ว: & \\
\hline e & $\mathrm{e}$ & ep & et & ak & em & en & an & er & i: & e: & $\mathcal{E}:$ & \\
\hline 0 & 0 & op & ot & ok & om & on & on & or & u: & $\varnothing:$ & ว: & $\mathrm{u}$ : \\
\hline
\end{tabular}

Table 28: After Short-High-Merger (Stage 5)

We get Core Amdo (Stage 6, Table 29) by the loss of vowel length. The formulation below likely includes some phonetic changes happening before.

Change 9 (Length-Loss) Long vowels become short vowels. Mid-low and high vowels conserve their vowel quality, mid-high vowels are raised to near-high, and /a:/ becomes /a/.

Length-Loss is necessarily preceded by Short-High-Merger, as it feeds ShortHigh-Merger. 


\begin{tabular}{c|cccccccccccc} 
& $\varnothing$ & b & d & g & m & n & ng & r & l & s & -ba & -bo \\
\hline a & a & ap & at & ak & am & an & ay & ar & a & I & a & u \\
i & ə & əp & ət & ək & əm & ən & ay & ər & i & i & $\varepsilon$ & \\
$\mathrm{u}$ & ə & əp & ət & ək & əm & ən & oy & ər & u & y & ว & \\
e & e & ep & et & ak & em & en & ay & er & i & I & $\varepsilon$ & \\
o & o & op & ot & ok & om & on & oy & or & u & y & ว & u
\end{tabular}

Table 29: Core Amdo (Stage 6)

\subsection{Relative dating}

Based on the relations of feeding and bleeding, the chronological precedence of the proposed sound changes is shown in Figure $4^{23}$. Included in the sound changes is the differentiated loss of front rounded vowels, which is necessarily preceded by /s/-Loss, which generates these vowels.

Also shown in Figure 4, as cross-sections, are the shared innovations marking the different stages of the evolution of Amdo Tibetan rhymes:

- /n/-Merger and /k/-Merger is shared by non-Amdo dialects as well.

- BAY seperated from mainstream Amdo Tibetan after having undergone /y/Merger, / $/$ /-Merger, as well as /s/-Loss and the sound changes that precede it.

- The Core Amdo reconstructed in this essay is characterized by $/ \mathbf{k} /$-Merger, Length-Loss and preceding changes.

- Finally, most modern dialects show the (albeit differentiated) loss of front rounded vowels.

\subsection{Absolute dating}

A few Chinese borrowings permit a better dating of the changes: ${ }^{\star} w u<$ pào (炮) 'gun' (\#783), ${ }^{\star}$ ladzu < làjiāo (辣椒) 'chilli' (\#505) and ${ }^{\star} \chi Y \chi Y<$ huíhuí (回回)

\footnotetext{
${ }^{23}$ In Figure 4, an arrow leading from one sound change to another indicates that the former necessarily precedes the latter. Figure 4 is a DAG (directed acyclic graph) in mathematical jargon. Chronological precedences, transitive (if rule A comes before rule B which comes before rule C, then A comes before $\mathrm{C}$ ) and antisymmetric (rule A cannot come before a rule B which comes itself before A), form a partial order, intuitively represented by a DAG. The DAG given is a transitive reduction: no arrow will connect a point $\mathrm{A}$ to a point $\mathrm{C}$ if one can go from $\mathrm{A}$ to $\mathrm{B}$ and from $\mathrm{B}$ to C.
} 


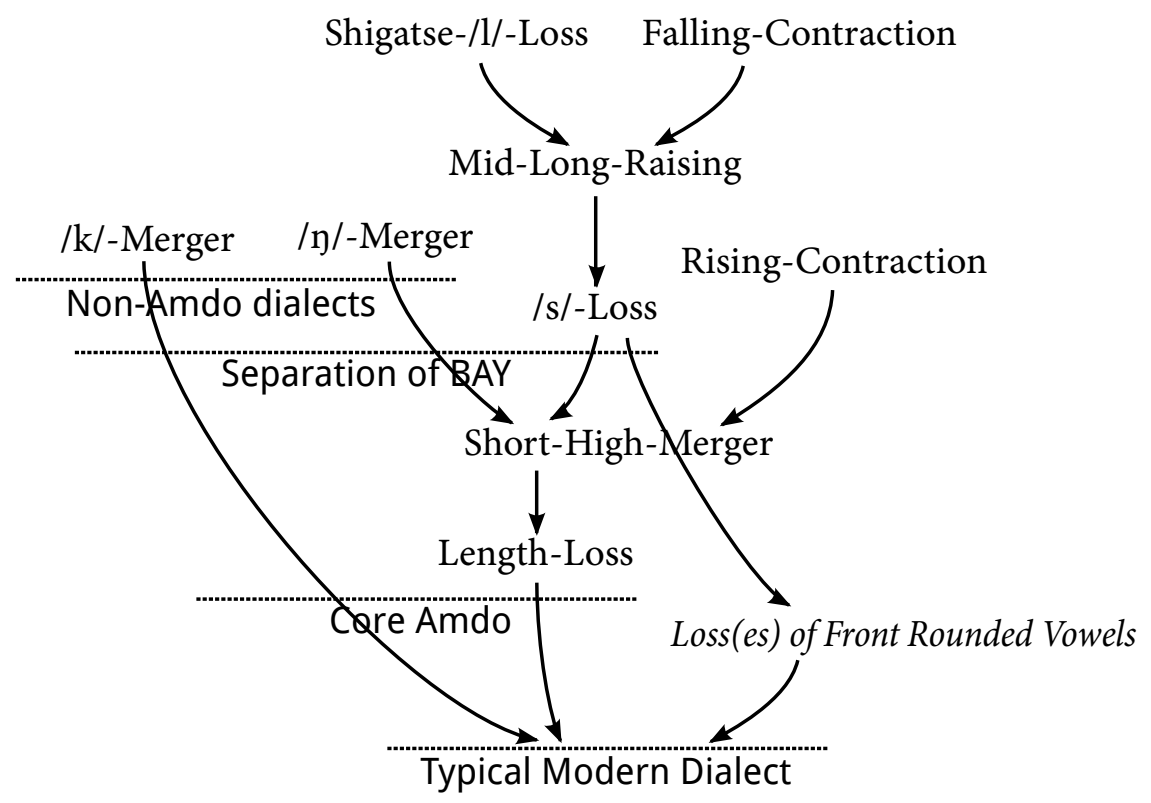

Figure 4: Relative dating of relevant sound changes

\begin{tabular}{|c|c|c|c|c|c|c|c|c|}
\hline CA & & BSA & REB & YAR & DMA & THE & BAY & \\
\hline$-\mathrm{u}$ & ${ }^{6} \mathrm{gu}$ & $\overline{\mathrm{wu}}$ & $\mathrm{u}$ & $\mathrm{wu}$ & $\mathrm{wu}$ & wu & $\mathrm{wu}$ & 783,1504 \\
\hline$-\mathrm{u}$ & 'chilli' & la.dzu & la.dzu & la.dzu & la.tcu & - & - & 505 \\
\hline$-Y$ & 'huíhuî' & $\chi e . x e$ & $\chi e . \chi e$ & $\chi e . \chi e$ & $\chi u \cdot \chi u$ & $\chi e \cdot \chi e$ & $\chi$ we. $\chi$ we & 211 \\
\hline
\end{tabular}

Table 30: Chinese loans in Amdo Tibetan

'Chinese-speaking Muslims' (\#211). Their modern reflexes are shown in Table 30. The lowered vowel $e$ in modern reflexes of ${ }^{\star} \chi Y \chi Y$ are likely due to effects of the initial $\chi$.

It is likely that làjiāo passed into Amdo Tibetan unmediated from Chinese. Neighbouring languages and dialects rarely show borrowing from Chinese làjiāo. Salar lazi (Lin, 1992), Modern Written Uyghur laza, both from Chinese làzi (辣 子). Hence the source form for the syllable jiāo must be either /t 60 :/ or something that sounds like /t6o:/ to a Tibetan ear, cf. Beijing Chinese tcjau, Lanzhou Chinese t6ว (Zhang and Mo, 2009), 'Phags-pa Chinese tsiew (Coblin, 2007, \#572).

Similarly for pào, Beijing $p^{h} a u$, Lanzhou $p^{h}$, 'Phags-pa $p^{h} a w(\# 531)$ which gives $\mathrm{CA}^{*}$-u. The loan form of pào, however, is not a direct loan from the Chinese, as is testified by its initial $w-<p$ - (cf. the common Amdo pronunciation of OT pad.ma as wan.ma), contrary to the aspirated Chinese form, cf. Gzhung.ba Tibetan pe:, Ham.phen pu: (Suzuki, 2009). The Gzhung.ba form, furthermore, 
supports the mid vowel height of the original, cf. Gzhung.ba ne: < OT nor, ze: $<$ OT zog, te: < OT sgro $b a^{24}$.

An original -o: corresponding to $\mathrm{CA}^{\star}$ - $\mathrm{u}$ can be fairly attributed to Mid-LongRaising, which, hence, must happen after the introduction of these two loans. While guns (including cannons) are ancient, the introduction of chilli is a quite datable event, necessarily after the Columbian explorations. More precisely, the first appearance of chilli in Chinese gazeteers is in 1671, while the first appreance in provinces bordering linguistic Tibet (Sichuan, Gansu, Yunnan) is 1737 in Gansu (Jiang and Wang, 2005). It can be safely assumed that chilli entered Amdo after or around 1737. The terminus post quem for Mid-Long-Raising can be hence determined at around the first part of 18th century.

Concerning huíhui, it gives the differentiated vowel reflexes just as a native word coming from Old Tibetan -os. The loss of front rounded vowels, hence, must be later than the date of the borrowing of huíhuí. The presence of Chinesespeaking Muslims in Amdo Tibet, however, is older than the introduction of chillis, while huíhuí is in usage already during the Yuan dynasty ${ }^{25}$ so this word has a rather limited utility for dating, the loss of the front rounded vowels necessarily postdating Mid-Long-Raising. However, it gives a nice confirmation of the dating of the sound changes.

\section{Conclusion}

Jacques (2011) represents a welcome change in the study of Tibetan dialects: it is

\footnotetext{
${ }^{24}$ The Gzhung.ba evidence is crucial because the intermediary is likely to be a Mongolic language: due to the near-absence of $p^{h}$ - in Mongolic languages, the word is usually adapted with the onset variously transcribed as $p$ - or b-: Khalkha Mongolian pu: (буy), modern Classical orthography in Inner Mongolia buu. If the Tibetan form is borrowed from late Central Mongolian, no raising is required in order to explain the present form in ${ }^{\star} u$. However, on the other side of the Mongolic world, the Turkic language Tuvan has borrowed this word in the form boo. The Gzhung.ba evidence is useful to determine whether the Tibetan form is borrowed from a late Central Mongolian form with a high vowel or a peripheral form with a non-high vowel.

The most likely explanation of the vowel discrepancy between late Central Mongolian and Tuvan is that the word had the form ${ }^{\star}$ bau at some point of its history. In native Mongolic words, if $v v$ is found in Central Mongolian and $o o$ in Mongolic loans in Tuvan, the only possible ProtoMongolic origins is *ahu (ayu in the Classical orthography) and *au (cf. Svantesson et al., 2005, p.184, Khabtagaeva, 2009, p.51-52): Classical Mongolian mayu 'bad', Khalkha Mongolian muv,

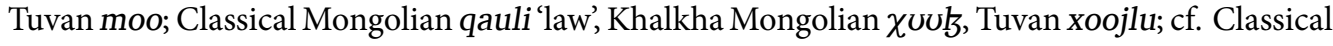
Mongolian buruyu 'guilt', Khalkha Mongolian puruv, Tuvan buruu.

${ }^{25}$ In the History of Song finished in 1345, during Yuan, for example, 諜聞北兵合西夏女真回回吐 蕃渤海軍五十餘萬大至 'According to the spies, the Northern armies, with allied Tangut, Jurchen, huíhuí, Tibetan and Parhae forces, came in great numbers, over 500 000.' (Tuotuo, History of Song, vol. 449, lièzhuàn 208, Cao Youwen, para. 28 835, accessed from Scripta Sinica database of IHP, Academia Sinica)
} 
a rare, if not the first (I do not know of other ones) effort to reconstruct the steps of "atomic" phonetic changes and the relative order thereof, from the Ursprache of Co.ne, a sister of Written Tibetan with a comparable phonological system, to the present-day Co-ne dialect. In order to provide a classification of Tibetan languages based on diagnostic innovation (Sun, 2003, p.798), this kind of step-bystep history should ideally be reconstructed for every documented dialect. This study, I hope, could be a step in the right direction.

The hypothesis that Amdo Tibetan historically had vowel length achieves a better explanation power than previous accounts of the diachrony of Amdo rhymes. By supposing an immediate step, it provides an better formulation of the rules and conditions of sound laws linking Old Tibetan to Amdo Tibetan. ${ }^{26}$

This reconstruction of the phonological history of Amdo Tibetan also permits a clearer vision of the evolution of Amdo Tibetan morphology, especially the forms of fused case forms of nouns, which will be the subject of a forthcoming study.

As a final note, I wish to bring to the attention of Tibetan dialectologists a characteristic vowel division of Amdo Tibetan: OT $-i s=-e l=-i l \neq-e s$. Exactly the same division is attested in Zhongu Tibetan (Sun, 2003, p.790), as ə vs. $i$. It is suggested that, for other non-tonal lengthless varieties of Tibetan, an intermediate step with distinctive length can be fruitfully postulated.

\section{Bibliography}

Nancy Jill Caplow. The role of stress in Tibetan tonogenesis: a study in historical comparative acoustics. PhD thesis, UC Santa Barbara, 2009.

Weldon South Coblin. A handbook of 'Phags-pa Chinese. University of Hawaii Press, 2007.

\footnotetext{
${ }^{26}$ It also provides an explanation of some exceptional modern forms, the most prominent being the irregular pronunciation of second-syllable vowel in disyllabic words in individual Amdo dialects. For example, in Mdo·la (Chinese: Qílián) Tibetan (data from the 1950s PRC dialect survey taken from Zhang, 2009) and occasionally in DMA, OT $a$ gives an actual form which corresponds to $\mathrm{CA}^{*} a$ : Mdo·la rdzə.ma < OT rdzi-ma 'eyelash', cf. ryæ < OT lnga 'five'; DMA hdza.ja OT dgra.ya 'enemy'. In Them.chen (Haller, 2004), the OT nominal suffix po $\sim b o$ is pronounced pu wu: çsəmpu < OT gsum.po 'those three' (p.58). Given that the stress pattern of disyllables (except compound verbs) was iambic in Old Tibetan and remained this way all along down to modern Amdo dialects (Caplow, 2009), these irregular reflexes can be explained by a stressinduced lengthening in a period preceding Mid-Long-Raising: $\mathrm{CA}^{\star} a<^{\star} a$ : lengthened from OT $a, \mathrm{CA}^{\star} u<{ }^{*} u:<_{\text {Mid-Long-Raising }}{ }^{\star} \mathrm{O}$ : lengthened from OT $o$. Some of the i's coming from OT $e$ might be explained in the same way.
} 
Scott DeLancey. Lhasa Tibetan. In Graham Thurgood and Randy J. LaPolla, editors, The Sino-Tibetan Languages, pages 270 - 288. London: Routledge, 2003.

Gesang-Jumian and Gesang-Yangjin. 藏语方言概论 Zàngyǔ fāngyán gàilùn (Introduction to Tibetan dialects). Beijing: Minzu Chubanshe, 2002. (Skal.bzang 'Gyur.med \& Skal.bzang Dbyangs.can).

Melvyn Goldstein and Nornang Nawang. Modern Spoken Tibetan: Lhasa Dialect. Seattle: University of Washington Press, 1970.

Felix Haller. Dialekt und Erzählungen von Shigatse, volume 13 of Beiträge zur tibetischen Erzählforschung. Bonn: VGH Wissenschaftsverlag, 2000.

Felix Haller. Dialekt und Erzählungen von Themchen: Sprachwissenschaftliche Beschreibung eines Nomadendialektes aus Nord-Amdo, volume 14 of Beiträge zur tibetischen Erzählforschung. Bonn: VGH Wissenschaftsverlag, 2004.

Nathan W. Hill. Tibetan $<$ h- $>$ as a plain initial and its place in Old Tibetan phonology. Linguistics of the Tibeto-Burman Area, 32(1), 2009.

Nathan W. Hill. An overview of Old Tibetan synchronic phonology. Transactions of the Philological Society, 108(2), 2010.

Nathan W. Hill. An inventory of Tibetan sound laws. Journal of the Royal Asiatic Society (Third Series), 21(04), 2011.

Kan Hua. 藏语安多方言词汇 Zàngyǔ Ānduō fāngyán cíhuì (A Vocabulary of Amdo dialect of Tibetan). Lanzhou: Gansu Minzu Chubanshe, 2002.

Kan Hua and Longbojia. 藏语安多口语词典 Zàngyǔ Ānduō kǒuyǔ cídiăn (A Dictionary of Amdo Vernacular of Tibetan). Lanzhou: Gansu Minzu Chubanshe, 1993. (Klu.'bum.rgyal).

Guillaume Jacques. Phonologie et morphologie du japhug (Rgyalrong). PhD thesis, Université Paris VII - Denis Diderot, 2004.

Guillaume Jacques. Le développement du tibétain ancien -e- dans les dialectes occidentaux. Etudes Mongoles \& Sibériennes, Centrasiatiques \& Tibétaines, 40, 2009.

Guillaume Jacques. A phonological profile of Cone Tibetan. Accessible at http:// halshs .archives-ouvertes. fr/halshs-00632301, 2011.

Mudong Jiang and Siming Wang. 辣椒在中国的传播及其影响 Làjiāo zài Zhōngguó de chuánbō jí qí yǐngxiăng (The spread of chilli and its influence in China). Zhongguo Nongshi, 2, 2005. 
Heinrich A. Jäschke. Tibetan Grammar. London: Trübner, 1883.

Bayarma Khabtagaeva. Mongolic elements in Tuvan, volume 81. Otto Harrassowitz Verlag, 2009.

Lianyun Lin. 撒拉汉一汉撒拉词汇 Sălā-Hàn/Hàn-Sălā Cíhuì (A Salar-Chinese) Chinese-Salar Lexicon). Chengdu: Sichuan Minzu Chubanshe, 1992.

Brian Newton. The Generative Interpretation of Dialect: A Study of Modern Greek Phonology, volume 8 of Cambridge studies in linguistics. Cambridge: Cambridge University Press, 1972.

Alan S. Prince. The phonology and morphology of Tiberian Hebrew. PhD thesis, Massachusetts Institute of Technology., 1975.

Aitang Qu. 阿里藏语Āľ̌ Zàngyǔ (Ngari Tibetan). Beijing: Zhongguo Shehui Kexue Chubanshe, 1983.

Aitang Qu. 藏语韵母研究 Zàngyǔ Yùnmǔ Yánjiū (A Study on Tibetan Rhymes). Xining: Qinghai Minzu Chubanshe, 1991.

András Róna-Tas. Tibeto-Mongolica: the Tibetan loanwords of Monguor and the development of the archaic Tibetan dialects. The Hague: Mouton, 1966.

Hongkai Sun. 阿坝藏语语音中的几个问题 Ābà Zàngyǔ yǔyīn zhōng de jǐgè wèntí (Aspects of Rngabba Tibetan phonetics). Minzu Yuwen, 2, 1987.

Jackson T.-S. Sun. Aspects of the phonology of Amdo Tibetan: Ndzorge Śæme Xrra dialect, volume 16 of Monumenta Serindica. Tokyo: Institute for the Study of Languages and Cultures of Asia and Africa, 1986.

Jackson T.-S. Sun. Phonological profile of Zhongu: A new Tibetan dialect of Northern Sichuan. Language and linguistics, 4(4), 2003.

Jackson T.-S. Sun. Special linguistic features of gSerpa Tibetan. Linguistics of the Tibeto-Burman Area, 29(1), 2006.

Jackson T.-S. Sun. Perfective stem renovation in Khalong Tibetan. In Roland Bielmeier and Felix Haller, editors, Linguistics of the Himalayas and Beyond, volume 196 of Trends in Linguistics, pages 323-340. The Hague: Mouton de Gruyter, 2007.

Kuo-ming Sung and Lha Byams Rgyal. Colloquial Amdo Tibetan: A complete course for adult English speakers. Beijing: China Tibetology Publishing House, 2005. 
Hiroyuki Suzuki. 川西民族走廊・チベット語方言分類語彙集 Sensei minzoku sōrō Chibetto-go hōgen bunrui goishū (Classified vocabulary of Tibetan dialects in the West-Sichuan Ethnic Corridor). Research Report 16102001-2, Japan Society for the Promotion of Science, 2009.

Jan-Olof Svantesson, Anna Tsendina, Anastasia Karlsson, and Vivan Franzén. The phonology of Mongolian. Oxford University Press, 2005.

Marius Zemp. Synchronic and diachronic phonology of the Tibetan dialect of Kargil. Master's thesis, Universität Bern, 2006.

Jichuan Zhang. 藏语词族研究 Zàngyǔ Cízú Yánjiūu (A Study on Word Families in Tibetan). Beijing: Shehui Kexue Wenxian Chubanshe, 2009.

Wenxuan Zhang and Chao Mo. 兰州方言词典 Lánzhōu Fāngyán Cídiǎn (Dictionary of Lanzhou Dialect). Beijing: Zhongguo Shehui Kexue Chubanshe, 2009.

Zhoumaocao. 玛曲藏语研究 Măqǔ Zàngyǔ Yánjiū (Study on rMa.chu Tibetan). Beijing: Minzu Chubanshe, 2004. ('Brug.mo.mtsho). 